SHRI KRISHNA JAYANTHI

\title{
O valor da ultra-sonografia na avaliação do traumatismo abdominal fechado
}

Tese apresentada à Faculdade de Medicina da Universidade de São Paulo para obtenção do título de Doutor em Ciências

Área de concentração: Radiologia

Orientador: Dr. Manoel de Souza Rocha

São Paulo

2008 


\title{
Dados Internacionais de Catalogação na Publicação (CIP)
}

\author{
Preparada pela Biblioteca da
}

Faculdade de Medicina da Universidade de São Paulo

Creprodução autorizada pelo autor

Jayanthi, Shri Krishna

O valor da ultra-sonografia na avaliação do traumatismo abdominal fechado / Shri Krishna Jayanthi. -- São Paulo, 2008.

Tese(doutorado)--Faculdade de Medicina da Universidade de São Paulo. Departamento de Radiologia.

Área de concentração: Radiologia.

Orientador: Manoel de Souza Rocha.

Descritores: 1.Ultra-sonografia 2.Ferimentos e lesões/diagnóstico 3.Traumatismos abdominais/diagnóstico 4.Tomografia computadorizada por raio $\mathrm{X}$ 
DEDICATÓRIA 
Para Vanessa,

Para Sofia,

Para meus pais Udaya Bhaskaram e Kasi Annapurna e

Para meus irmãos Shriram e Shridhar

por todo o amor, ajuda e compreensão incondicionais nessa jornada 
AGRADECIMENTOS 
Ao Dr. Manoel de Souza Rocha, pela orientação nessa tese, por todo o apoio e amizade oferecidos e pela minha formação radiológica e humana.

Ao Dr. Marcos Roberto de Menezes, pelo constante apoio, amizade e sugestões ao longo do trabalho.

Ao Prof. Dr. Giovanni Guido Cerri, pelo apoio e por possibilitar toda a infra-estrutura na realização do trabalho.

Aos meus colegas radiologistas do Pronto-Socorro do Hospital das Clínicas da FMUSP, Dr. Alexandre Maurano, Dr. Antonio Furtado de Albuquerque Cavalcanti, Dr. Celso Kamiya, Dr. Flávio Ferrarini Oliveira Pimentel, Dr. João Carlos Rodrigues, Dr. Gabriel S. Gattás, Dra. Kazumi Katakaoka e Dr. Walther Yoshiharu Ishikawa, pelo constante apoio, companheirismo e amizade.

Aos residentes de radiologia do INRAD/HCFMUSP, pelo constante desafio da aprendizagem e pelo apoio na coleta dos dados.

À equipe de Cirurgia de Emergência do PS/HCFMUSP, pelo mútuo e constante aprendizado.

A toda equipe de enfermagem do PS/HCFMUSP pelo apoio durante a realização do trabalho.

À Sra. Sandra de Barros, secretária de Pós-Graduação, pelo inestimável auxílio nos trâmites e pelo constante apoio.

A todos os funcionários das Bibliotecas Central e do INRAD, pela disponibilidade ao auxílio durante o trabalho.

A toda minha família, que me permitiu uma estrutura adequada para realizar o trabalho. 
"Simplicidade e unidade são as duas verdadeiras fontes da beleza" Johann Joachim Winckelmann 
Esta tese está de acordo com as seguintes normas, em vigor no momento desta publicação:

Referências: adaptado de International Comittee of Medical Journals Editors (Vancouver)

Universidade de São Paulo. Faculdade de Medicina. Serviço de Biblioteca e Documentação. Guia de apresentação de dissertações, teses e monografias. Elaborado por Annelise Carneiro da Cunha, Maria Julia de A. L. Freddi, Maria F. Crestana, Marinalva de Souza Aragão, Suely Campos Cardoso, Valéria Vilhena. $2^{a}$ Ed. São Paulo: Serviço de Biblioteca e Documentação; 2005.

Abreviaturas dos títulos dos periódicos de acordo com List of Journals Indexed in Index Medicus. 


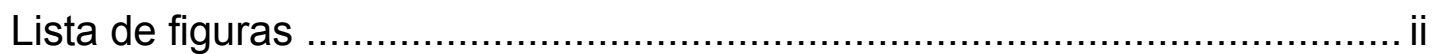

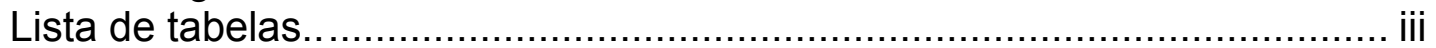

Lista de abreviaturas..........................................................................

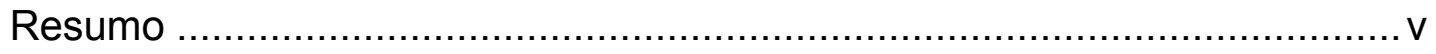

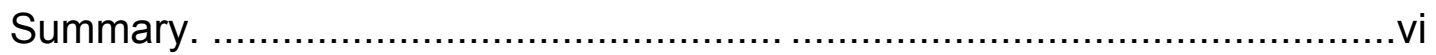

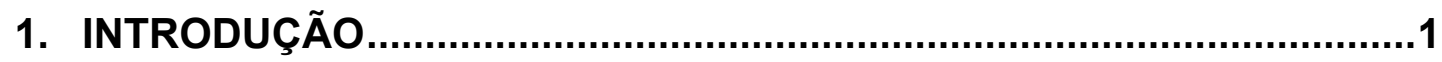

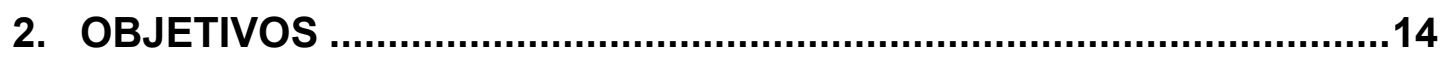

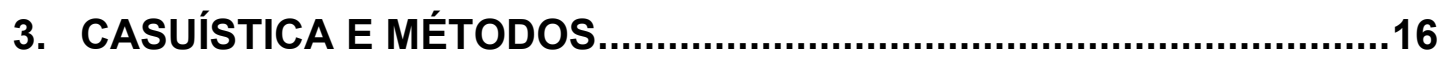

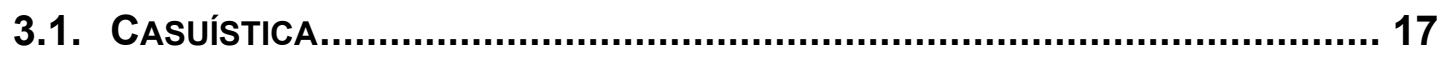

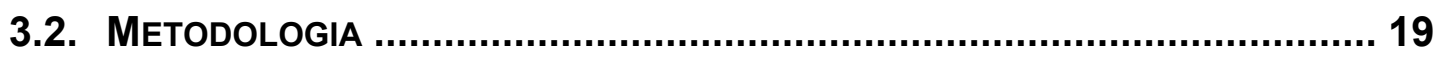

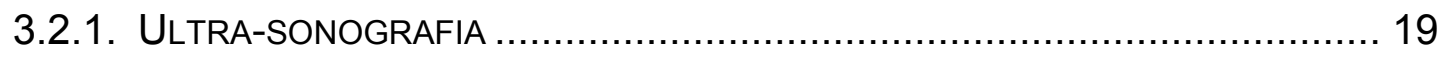

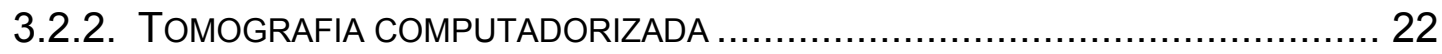

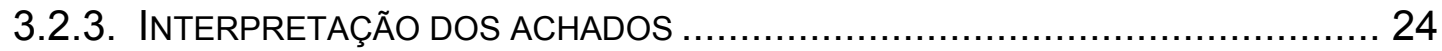

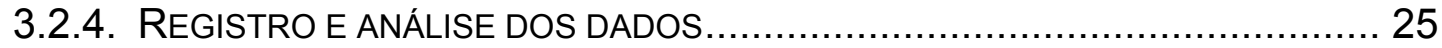

4. RESULTADOS

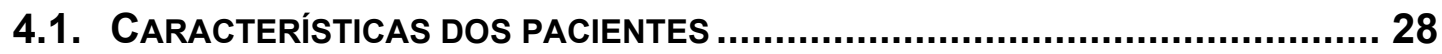

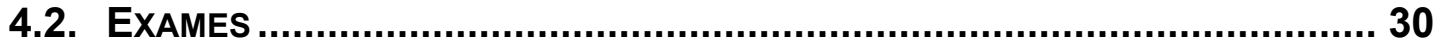

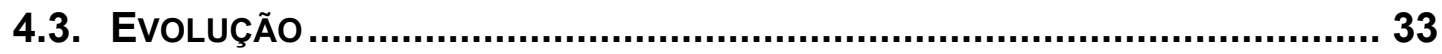

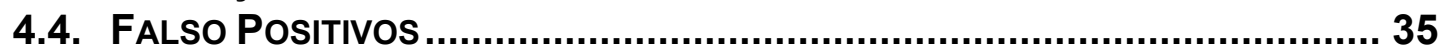

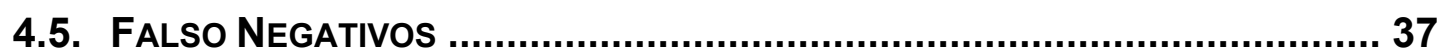

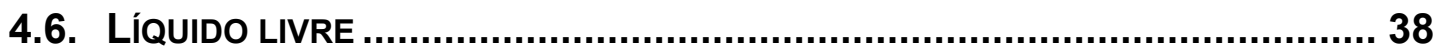

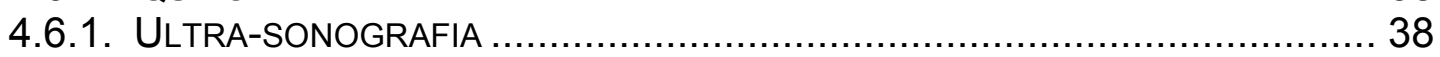

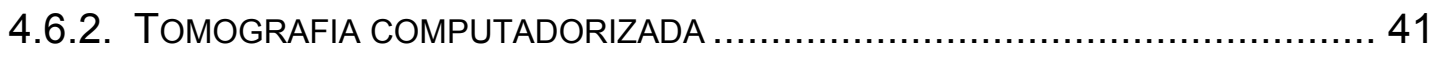

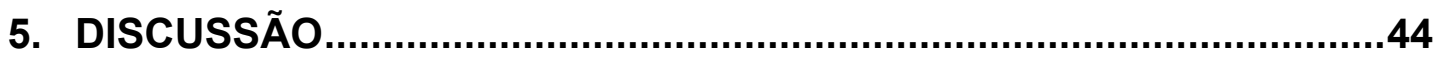

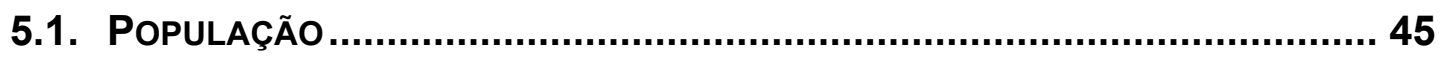

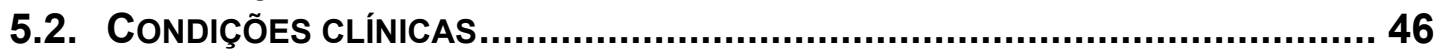

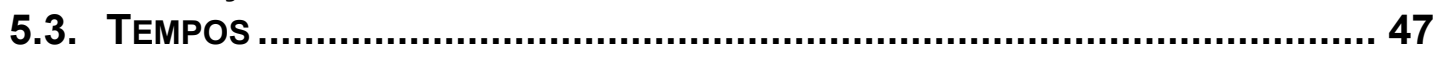

5.4. EXPERIÊNCIA DO EXAMINADOR...................................................... 53

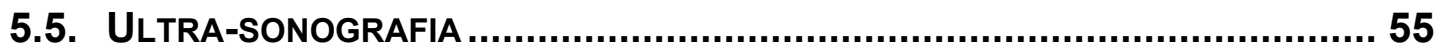

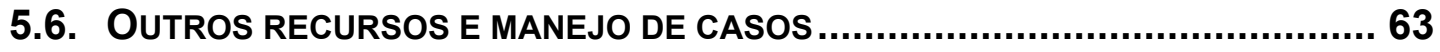

6. CONCLUSÃO

ANEXOS

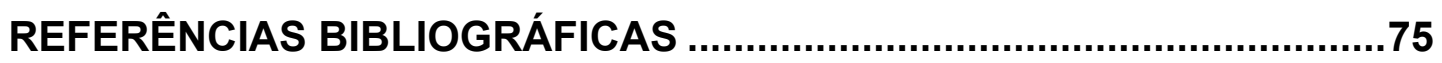




\section{LISTA DE FIGURAS}

FIGURA 1: ULTRA-SONOGRAFIA PROTOCOLO FAST REALIZADA NA SALA DE EMERGÊNCIA, EM SINTONIA COM AS MANOBRAS DE ATENDIMENTO INICIAL HOSPITALAR

FIGURA 2 - PROTOCOLO DE QUATRO QUADRANTES DO FAST

COMPREENDENDO JANELA PERICÁRDICA (1), ESPAÇO HEPATORRENAL

(2), ESPAÇO ESPLENORRENAL (3) E PELVE (4)

FIGURA 3 IMAGENS ULTRA-SONOGRÁFICAS DOS QUATRO QUADRANTES DO EXAME 21

FIGURA 4 IMAGENS ULTRA-SONOGRÁFICAS DOS QUATRO QUADRANTES DO EXAME EVIDENCIANDO LÍQUIDO LIVRE. 21

FIGURA 5 - EXAME POSITIVO COM GRANDE VOLUME DE LÍQUIDO LIVRE NA PELVE: A RESPOSTA É IMEDIATA

FIGURA 6 - LACERAÇÕES HEPÁTICAS SUPERFICIAIS. À US NOTA-SE HETEROGENEIDADE DA SUPERFÍCIE HEPÁTICA, QUE À TC EVIDENCIOU LACERAÇÕES MAIS PROFUNDAS 59

FIGURA 7 - LACERAÇÃO ESPLÊNICA COM HEMATOMA SUBCAPSULAR. À ULTRA-SONOGRAFIA NOTA-SE ALTERAÇÃO DO CONTORNO ESPLÊNICO COM PEQUENA LÂMINA HIPOECOGÊNICA JUNTO À CAPSULA ESPLÊNICA 60

FIGURA 8 - PACIENTE COM US INICIAL NEGATIVO, APRESENTANDO

HEMATÚRIA. SUSPEITA INICIAL DE LESÃO VESICAL POR FRATURA DE BACIA, LEVANDO À REALIZAÇÃO DE TOMOGRAFIA COMPUTADORIZADA QUE DEMONSTROU VOLUMOSO HEMATOMA PERIRRENAL 61

FIGURA 9 - TC EVIDENCIANDO HEMATOMA RETROPERITONEAL (SETAS BRANCAS) SECUNDÁRIAS A FRATURA DO SACRO (SETAS AMARELAS) 62

FIGURA 10 - ALGORITMO DE AVALIAÇÃO DO TRAUMA 67 


\section{LISTA DE TABELAS}

TABELA 1- DISTRIBUIÇÃO DE CASOS DE ACORDO COM A FAIXA ETÁRIA ..................28

TABELA 2 - DISTRIBUIÇÃO DE CASOS DE ACORDO COM AS CAUSAS DE TRAUMA .....29

TABELA 3 - DistribuiçÃo de CASOS DE ACORDO COM A ESCALA DE COMA DE

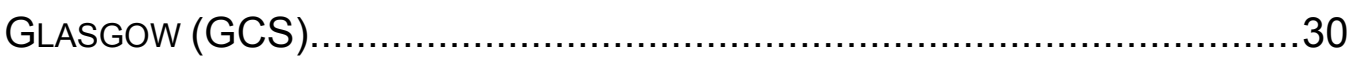

TABELA 4 - DISTRIBUIÇÃO DE CASOS DE ACORDO COM A EXPERIÊNCIA DO

EXAMINADOR.

TABELA 5 - DISTRIBUIÇÃO DE CASOS DE ACORDO COM OS RESULTADOS DE US

E TC

TABELA 6 - REDISTRIBUIÇÃO DE CASOS COM CORREÇÃO DO RESULTADO DA TOMOGRAFIA COMPUTADORIZADA

TABELA 7 - DISTRIBUIÇÃO DE CASOS DE ACORDO COM A EVOLUÇÃO, EM

RELAÇÃO À US 33

TABELA 8- NECESSIDADE DE CIRURGIA EM RELAÇÃO À US .33

TABELA 9 - DISTRIBUIÇÃO DE CASOS DE ACORDO COM A EVOLUÇÃO, EM RELAÇÃO À TC 34

TABELA 10 - NECESSIDADE DE CIRURGIA EM RELAÇÃO À TC .35

TABELA 11- DISTRIBUIÇÃO DO ACHADO DE LÍQUIDO NA US .40

TABELA 12 - DISTRIBUIÇÃO DO ACHADO DE LÍQUIDO NA TC SEM OUTRAS LESÕES INTRA-ABDOMINAIS DETECTÁVEIS. .42

TABELA 13 - DistRIBUIÇÃO DO ACHADO DE LÍQUIDO NA TC ASSOCIADA A LESÕES INTRA-ABDOMINAIS .43 


\title{
LISTA DE ABREVIATURAS
}

\author{
ATLS Advanced Trauma Life Support \\ FAST Focused Assessment with Sonography for Trauma/ Avaliação Ultra- \\ sonográfica Focalizada para Trauma \\ FN Falso Negativo \\ FP Falso Positivo \\ GCS Glasgow Coma Scale/Escala de Coma de Glasgow \\ PS Pronto-Socorro \\ TC Tomografia Computadorizada \\ US Ultra-sonografia \\ VPN Valor Preditivo Negativo \\ VPP Valor Preditivo Positivo
}


Jayanthi SK. O valor da ultra-sonografia na avaliação do traumatismo abdominal fechado[tese]. São Paulo: Faculdade de Medicina, Universidade de São Paulo; 2008, 94p.

O trauma é uma das principais causas de morbidade e mortalidade em uma faixa etária que compreende adolescentes e adultos jovens, em proporção dominante do sexo masculino, com grande impacto econômico e social. Dentro do complexo do trauma, o traumatismo abdominal fechado (TAF) é um evento bastante freqüente e apresenta dificuldade na avaliação e manejo, uma vez que o exame clínico apresenta baixa sensibilidade e especificidade. A deteç̧ão de hemoperitônio é um dos métodos de avaliação indireta de possíveis lesões intra-abdominais, inicialmente pela punção abdominal diagnóstica e posteriormente pela lavagem peritoneal diagnóstica, que, apesar da eficácia, apresentam inconvenientes invasividade e impossibilidade na quantificação do hemoperitônio e no estadiamento da lesão, resultando em laparotomias não-terapêuticas. Os métodos de imagem prestam utilidade na investigação de lesões intra-abdominais, como a radiografia convencional e contrastada, ultra-sonografia (US) e a tomografia computadorizada (TC), esta última o método que apresenta melhor resolutividade, porém como desvantagens o custo, acessibilidade, o uso de radiação ionizante e meio de contraste e o deslocamento do paciente até o aparelho. A US apresenta-se como alternativa na avaliação inicial destes pacientes como método não invasivo e com potencial de dano virtualmente ausente, de baixo custo, de rápida realização e portátil. Apesar disso, este método também apresenta suas limitações, como na de lesões intra-abdominais na ausência de líquido livre. Este estudo foi realizado com a finalidade de estabelecer o desempenho da US neste contexto, permitindo racionalizar o uso da TC. Com essa finalidade foram estudados 163 pacientes atendidos pelo PS-HC/FMUSP, com a realização consecutiva de US e TC. A população estudada enquadra-se no perfil usual das vítimas de trauma, sendo $83 \%$ do sexo masculino e $56 \%$ na faixa etária entre 20 e 39 anos e em $73 \%$ dos casos eram vítimas de acidentes de trânsito. Eles foram trazidos ao serviço num tempo médio de 51 minutos, na maior parte estáveis e com nível de consciência satisfatório. A US levou em média 5 minutos para ser realizada e o intervalo médio até a realização da TC foi de155 minutos. Dos 163 pacientes $31(19 \%)$ apresentaram US positiva e $132(81 \%)$ apresentaram US negativa. Dos mesmos 163 pacientes $33(20,2 \%)$ apresentaram TC positiva e $130(79,8 \%)$ apresentaram TC negativa, resultando em sensibilidade de $73 \%$, especificidade de $95 \%$, acurácia de $90 \%$ em prevalência de $20 \%$, com valor preditivo positivo de $77 \%$ e valor preditivo negativo de $93 \%$. Corrigindo quanto à detecção de líquido livre, resulta-se em sensibilidade de $64 \%$, especificidade de $98 \%$, acurácia de $89 \%$ em prevalência de $27,6 \%$ e valor preditivo positivo de $93 \%$ e valor preditivo negativo de $88 \%$. Ao se considerar a evolução dos pacientes, o desempenho da US foi semelhante ao da TC. Ao se considerar a necessidade de cirurgia a US apresentou acurácia de $87 \%$, com valor preditivo positivo de $58 \%$ e valor preditivo negativo de $94 \%$, próximo da TC, com $91 \%$ de acurácia, $67 \%$ de valor preditivo positivo e $97 \%$ de valor preditivo negativo. $24 \%$ dos pacientes com lesões intra-abdominais não apresentavam líquido livre, registrados pela TC. O espaço hepatorrenal e a pelve são os locais mais freqüentes do encontro de líquido, sendo $74 \%$ e $67 \%$ à US e $51 \%$ e $62 \%$ à TC, respectivamente. Entre os fatores que indicaram tendência de necessidade cirúrgica destaca-se a presença de líquido no espaço hepatorrenal (14 de 20 pacientes) e somatória dos bolsões de líquido acima de $3,0 \mathrm{~cm}$. A detecção de lesões em víscera parenquimatosa foi baixa: 4 casos em 33, sendo que apenas 2 deles se confirmaram. Dentre os fatores que limitam o estudo pela US estão as lesões intraparenquimatosas que não se associam a líquido livre e hematomas retroperitoneais. A experiência do examinador não influenciou no número de casos positivos ou negativos, mas notou-se uma tendência a falso-positivos em examinadores mais experientes e falso-negativos em menos experientes. Assim, a US apresenta-se como ferramenta útil na avaliação inicial de traumatismo abdominal fechado, fornecendo subsídios para avaliação clínica, que associado aos demais dados, permite determinar a conduta.

Descritores: 1.Ultra-sonografia 2.Ferimentos e lesões/diagnóstico 3.Traumatismos abdominais/diagnóstico 4.Tomografia computadorizada por raio $\mathrm{X}$ 
Jayanthi SK. Value of ultrasound in the evaluation of blunt abdominal trauma [thesis]. São Paulo: Faculdade de Medicina, Universidade de São Paulo; 2008, 94p.

Trauma is a major cause of morbidity and mortality in an age group including from teenagers to young adults, in a male dominat proportion, resulting in great economic and social impact. Within the complex of trauma, blunt abdominal trauma (BAT) is frequent event and presents difficulty in the evaluation and management since the clinical examination shows low sensitivity and specificity. The detection of hemoperitoneum is one of the methods of evaluation of possible indirect intra-abdominal injuries, initially using direct diagnostic abdominal paracentesis and posteriorly the diagnostic peritoneal lavage, that despite the effectiveness, have drawbacks such as invasiveness and the inability of hemoperitoneum quantification and the lesion staging, resulting in non-therapeutic laparotomies. Imaging methods provide useful information in the investigation of abdominal injuries, such as conventional and contrast radiology, ultrasound (US) and computed tomography (CT), which is the best effective method, but has its own drawbacks, such as cost, accessibility, use of ionizing radiation and contrast media and the displacement of the patient to the machine. US presents itself as an alternative in the initial evaluation of these patients as noninvasive method, with lack of harmfulness, low cost, fast answer and portability. Nevertheless, this method also has its limitations, as in cases of abdominal injuries without free fluid. This study was conducted in order to establish the performance of the US in this setting, allowing to rationalise the use of CT. For this purpose we studied 163 patients treated in the ER of $\mathrm{HC} / \mathrm{FMUSP}$, with the completion of consecutive US and CT. The population fits the usual profile of trauma victims, with $83 \%$ male, $56 \%$ in the age group between 20 and 39 years and in $73 \%$ of cases victims of traffic accidents. They were brought to the service in an average time of 51 minutes, mainly stable and with satisfactory level of consciousness. US took on average 5 minutes to be performed and the average interval until CT completion was 155 minutes. $31(19 \%)$ of 163 patients showed positive US and $132(81 \%)$ had negative US. $33(20.2 \%)$ of the same 163 patients had positive CT and $130(79.8 \%)$ had negative CT, resulting in a sensitivity of $73 \%$, specificity of $95 \%$, accuracy of $90 \%$ in $20 \%$ prevalence, with $77 \%$ of positive predictive value and $93 \%$ of negative predictive value. Correcting the detection of free fluid, results in $64 \%$ of sensitivity $98 \%$ of specificity $89 \%$ of accuracy in $28 \%$ of prevalence, with $93 \%$ of positive predictive value and $88 \%$ of negative predictive value of $88 \%$. Considering the evolution of the patients, US performance was similar to that of CT. Considering need for surgery the US presented accuracy of $87 \%$, positive predictive value of $58 \%$ and negative predictive value of $94 \%$, near CT, with accuracy of $91 \%$, predictive value of $67 \%$ and negative predictive value of $97 \% .24 \%$ of patients with abdominal injuries did not have free fluid, as recorded by CT. The hepatorrenal space and pelvis were the most frequent sites fluid finding, $74 \%$ and $67 \%$ at US and $51 \%$ and $62 \%$ at CT, respectively. Among the factors that showed a tendency for surgery requirement were the presence of fluid in hepatorrenal space (14 of 20 patients) and the sum of liquid pockets over $3.0 \mathrm{~cm}$. Detection of parenchymal lesions was low: 4 cases in 33, while only 2 of them confirmed. Among the factors that limit the US study are parenchymal lesions not associated with free fluid and retroperitoneal hematomas. Examiner experience did not influence the number of negative or positive cases, but there was a tendency to false positive with most experienced examiners and false negative with less experienced. Thus, US is an useful tool in the initial evaluation of blunt abdominal trauma, providing information for clinical evaluation, which associated with other data, tailors the management.

Descriptors: 1.Ultrasonography 2.Wounds and Injuries/diagnosis 3.Abdominal Injuries/diagnosis 4.Tomography, X-Ray Computed 
1. INTRODUÇÃO 
O politraumatismo ocorre em eventos cinéticos, as principais variáveis sendo a velocidade e a massa, envolvendo impacto de moderado a alto grau e concomitante dissipação de energia, com lesões em diversas localidades no corpo e em múltiplos órgãos.

A determinação do mecanismo do trauma e dos potenciais sítios de lesão é muito dificultada num primeiro momento. Os sintomas e sinais externos iniciais podem ser ilusórios, superestimados ou subestimados, sendo o exame clínico de baixa sensibilidade e especificidade (Schurink et al. 1997) e esta avaliação é pior com os pacientes com nível de consciência reduzido (Wilson et al. 1965).

Desta forma a determinação de um órgão-alvo de lesão é inadequada, sendo a conduta atualmente preconizada a avaliação global, protocolada de maneira sistemática e hierárquica dos diferentes sistemas, com prioridade na avaliação e rápida intervenção, se necessária, daqueles considerados vitais.

Em termos populacionais, o politraumatismo é um das principais causas de morbidade e mortalidade na faixa que engloba os adolescentes e adultos, envolvendo em menor grau crianças e idosos (Shuster et al. 2004). Nota-se também uma preponderância do sexo masculino. Considerando os dois primeiros grupos citados, que correspondem a um grupo economicamente ativo, o impacto social e econômico do politraumatismo é grande (MacKenzie et al. 1990). 
No Brasil as causas externas foram responsáveis por 48,5\%, 80,2\% e $52,5 \%$ dos óbitos respectivamente das faixas etárias de 10 a 19 anos, 20 a 29 anos e 30 a 39 anos, para pessoas do sexo masculino em 2004, representando no pico 209,5 óbitos/100 mil habitantes na faixa etária entre os 20 e 24 anos (Ministério da Saúde/Brasil 2006).

O impacto estimado das mortes por causa externa, incluindo a violência é de aproximadamente 20 bilhões de reais, calculada para o ano de 2001 segundo estudo do IPEA (Carvalho et al. 2007). Para reduzir este impacto, as ações necessárias são amplas e envolvem esforços em diversas frentes, desde sanitárias, como redução do consumo de álcool (Hingson et al. 1996), de infra-estrutura como melhoria das vias de tráfego e aumento de segurança para pedestres, industrial ao se utilizar e projetar novos equipamentos e metodologias de segurança, legais, utilizando-se regras mais rígidas, associadas a educação específica ao trânsito (Robertson 1996) e no sentido específico da violência, ao se reduzir índices de pobreza e desigualdade social.

Historicamente, o tratamento de feridas foi um dos pilares do desenvolvimento da medicina e cirurgia. Em especial atenção às feridas contusas, o tratamento sempre foi conservador. As maiores mudanças no tratamento das feridas vieram com as guerras modernas a partir do século 19 caracterizadas por: implantação da evacuação, progressivamente mais rápida, dos feridos da linha de frente para retaguardas, onde foram criados postos de atendimento avançado, cuidados de higiene e limpeza das feridas 
e posterior assepsia e anti-sepsia, cicatrização por primeira intenção e a incorporação das enfermeiras no auxílio do cuidado dos doentes (Hoyt et al. 1988). A resposta a estas medidas foi positiva com a redução da mortalidade pela recuperação de um maior número de enfermos, ainda que com seqüelas.

No plano civil, o desenvolvimento tecnológico no século $X X$, com a era motora resultando em meios de transporte cada vez mais individuais e rápidos e a possibilidade de construções altas, tem resultado em eventos traumáticos de intensidade crescente, com conseqüente complexidade quanto ao número de órgãos e sistemas envolvidos, ao mecanismo de lesão e à intensidade das lesões nestes. Soma-se a isto, o fato da popularização e disseminação desses agentes, o que resulta em um número de eventos traumáticos elevado, gerando a necessidade de uma estrutura de atendimento pré-hospitalar e hospitalar adequado. Convém lembrar que os eventos automotores não são os únicos fatores predisponentes ao politraumatismo, ainda somando os eventos usuais de alto impacto, sendo as principais as quedas de altura, contusões com objetos pesados e ferimentos contusos em geral de múltiplas etiologias.

O grande marco em termos de saúde pública no atendimento destes pacientes veio a partir da publicação em 1966 do documento "Accidental Death and Disabily: The Neglected Disease of Modern Society" pelo Comitee on Trauma and Comitee on Shock do National Academy of Science/National Research Council, em que se alertou sobre o descaso e a não-uniformidade 
no tratamento destes pacientes que demonstrou ser o politraumatismo uma doença de grande impacto social.

$\mathrm{Na}$ década de 60, em Maryland, foi criado o conceito de "Golden Hour" (Cowley et al. 1973), no qual se definiu empiricamente o período de uma hora, a partir do momento da injúria, para que o paciente seja encaminhado e atendido num centro hospitalar capacitado e até tratado com intervenção cirúrgica se necessário, com intuito de reduzir a mortalidade destes pacientes.

Trunkey (1983) descreveu uma distribuição trimodal dos óbitos após um evento de trauma. O primeiro pico de óbitos, correspondendo a aproximadamente metade deles, ocorre imediatamente após o evento e decorre de lesões cerebrais graves, cardíacas ou aos grandes vasos e a morte é inevitável nestes casos; o segundo pico de óbitos, correspondendo a aproximadamente um terço deles, ocorre nas primeiras horas após o evento sendo as causas lesões cerebrais e hemorragia e o restante dos óbitos ocorre dias a semanas após os eventos, já em ambiente hospitalar, decorrente também de complicações dos eventos iniciais.

Ainda na década de 80, o American College of Surgeons implantou o "Advanced Trauma Life Support" (ATLS), com o intuito de treinar e padronizar o atendimento destes pacientes, definindo uma equipe multiprofissional e dividindo a avaliação e conduta por sistemas orgânicos e prioridades específicas. 
O protocolo do American College of Surgeons específico para o trauma, o Advanced Trauma Life Support (Suporte de Vida Avançado no Trauma), preconiza a seguinte ordem, registrada num mnemônico:

A - permeabilização das vias aéreas e imobilização cervical;

B - ventilação e respiração;

C - avaliação do sistema circulatório, vias de acesso endovenoso e estancamento de hemorragias externas;

D - avaliação do estado de consciência e déficits neurológicos;

E - exposição e avaliação global do corpo,

Após estas medidas iniciais emergenciais, é realizada uma avaliação secundária envolvendo diversos órgãos e sistemas: instabilidade de bacia, toque retal, sondagens, fraturas, entre outros.

Dentro do complexo do politraumatismo, o traumatismo abdominal fechado é um evento bastante freqüente e com certa dificuldade quanto à sua avaliação e manejo. Sua particularidade reside na possibilidade de lesões em graus variáveis em diferentes estruturas intra-abdominais, sem a presença de lesões externas ou com poucos sintomas abdominais.

A detecção do hemoperitônio foi considerada como um dos meios de avaliação de possíveis lesões traumáticas intra-abdominais sendo que um dos primeiros métodos preconizados para sua deteç̧ão foi a punção abdominal diagnóstica, que apresenta baixa sensibilidade, mesmo utilizando-se a técnica de quatro quadrantes (Perry 1965). 
Posteriormente o recurso propedêutico que apresentou grande impacto nestes casos foi a lavagem peritoneal diagnóstica (Root et al. 1965). Consiste num procedimento invasivo, que envolve um pequeno procedimento cirúrgico, com a introdução de uma sonda na cavidade peritoneal com infusão de soro fisiológico, posteriormente recuperado e analisado. A positividade do exame é determinada pela presença de sangue neste material recuperado que somado aos demais dados clínicos e laboratoriais resultava na conduta a ser tomada. Ainda persiste como principal método de avaliação de hemoperitônio em alguns centros desapercebidos de equipamentos de diagnóstico por imagem que não a radiografia convencional. Tal procedimento, apesar da alta sensibilidade, envolve alguns inconvenientes, sendo os principais: consistir um procedimento cirúrgico com seus riscos, não conseguir quantificar o hemoperitônio e não permitir a determinação do órgão-alvo e o grau da lesão, que muitas vezes é auto-limitada, além de reveses menores e infreqüentes como resultados dúbios e não-aplicabilidade em alguns casos, levando a inferências erradas com conseqüente impacto sobre as condutas (Fischer et al. 1978; Hawkins et al. 1990).

O diagnóstico por imagem sempre se prestou a auxiliar na avaliação do traumatismo, sendo a radiologia convencional a primeira modalidade disponível. Esta permite uma avaliação inicial abdominal bastante limitada, porém sensibilizando a suspeita de lesões através da detecção de pneumoperitônio (achado pouco freqüente), de significativas quantidades de líquido, de alterações na distribuição de alças e da concomitância de fraturas 
(costelas, bacia e coluna). Ressalve-se que esta última particularidade ainda é bastante útil atualmente.

Posteriormente, com o desenvolvimento de meios de contraste radiológicos, a radiologia contrastada permitiu a avaliação, ainda que parcial e algo limitada, de lesões específicas, particularmente: segmentos de vísceras ocas (estudos contrastados gastrointestinais), estruturas vasculares e órgãos parenquimatosos como fígado, rins e baço (radiologia vascular e urografia excretora) e para avaliação de trauma uretral; possivelmente esta e a radiologia vascular ainda as únicas indicações formais da modalidade e eventual tratamento, no caso da radiologia vascular. Não são superiores à lavagem peritoneal diagnóstica quanto ao hemoperitônio, mas permitiam avaliação específica de lesões em órgãos-alvo (Mindelzun et al. 1984).

Com o desenvolvimento tecnológico e disseminação de equipamentos, os meios de diagnóstico por imagem passaram a exercer importante papel nesta avaliação, principalmente pela ultra-sonografia e pela tomografia computadorizada (Federle et al. 1981), além da medicina nuclear (Gelfand 1984).

A tomografia computadorizada é considerada atualmente como padrão-ouro para avaliação do traumatismo abdominal (Goldstein et al. 1985; Linsenmaier et al. 2002), pois permite uma ampla avaliação abdominal, detectando desde pequenas quantidades de líquido livre, inferindo hemoperitônio, bem como minuciosa avaliação de estruturas parenquimatosas e vísceras ocas (esta um pouco mais limitada), mesentério, retroperitônio e parede abdominal. Muitas vezes é o principal 
exame na determinação da conduta, se expectante ou não. Apresenta como principais fatores limitantes: o uso de equipamento ainda não tão difundido no nosso meio e que apresenta investimento inicial e de manutenção altos, resultando num exame com um custo relativamente elevado; a necessidade de transporte do paciente até o equipamento, que pode ser inconveniente em alguns casos em virtude das condições clínicas; o uso de contraste endovenoso, que têm potencial alergênico e nefrotóxico e a exposição à radiação ionizante.

Considerando-se o risco/benefício num contexto de trauma abdominal fechado com potencial lesão intra-abdominal, esses últimos dois fatores e o deslocamento do paciente, passam a ser riscos menores, onde o benefício do exame compensaria os riscos expostos. Ainda assim, persiste a questão do custo do exame, que individualmente seria relativamente baixo, porém considerando-se o movimento de um serviço de emergências com um grande número de casos de politraumatismo, tal custo poderia tornar-se proibitivo. Um segundo fator a ser considerado é a ocupação da sala, em que sua rotina momentânea e subitamente fosse interrompida para a realização de um exame um pouco mais complexo. Desta forma, seu uso otimizado, indicando-o apenas nos casos onde há potencial efetivo de lesão abdominal, depende de uma adequada seleção de pacientes que se beneficiariam deste procedimento (Schreiber et al. 1996).

A ultra-sonografia foi primeiramente utilizada como método alternativo para a detecção de lesões intra-abdominais no final da década de 60 (Holm et al. 1968a,b), sendo que os dois primeiros hematomas intra-abdominais a 
serem diagnosticados por este método foram espontâneos esplênicos (Kristensen et al. 1971). Ainda na década de 70 foi publicado o primeiro trabalho utilizando-se a ultra-sonografia para detecção de lesão traumática esplênica, baseado apenas na sua morfologia (Asher et al. 1976).

Em 1983 foi descrito o uso da ultra-sonografia para detecção de lesão diafragmática (Ammann et al. 1983). Posteriormente outros trabalhos foram demonstrando mais vantagens da ultra-sonografia, estabelecendo-se como método alternativo à lavagem peritoneal diagnóstica (Rozycki 1995).

Tal metodologia também se beneficiuou da evolução tecnológica, que permitiu o desenvolvimento de equipamentos cada vez menores chegando aos modelos de pequeno porte e os portáteis, que permitem o deslocamento até o leito do paciente.

Atualmente a ultra-sonografia é efetivamente utilizada como método inicial para detecção de líquido livre intraperitoneal, recebendo o acrônimo de FAST - Focused Assessment with Sonography for Trauma (Avaliação Ultra-sonográfica Focalizada para Trauma). O exame é realizado na própria sala de emergência, pelo radiologista de plantão da equipe do prontosocorro, ainda durante o atendimento inicial, junto com a exposição e avaliação global ( Figura 1). A dinâmica deste exame nesse contexto envolve grande interação com o restante da equipe de atendimento, com o resultado imediatamente comunicado, permitindo a tomada das decisões de maneira rápida. 


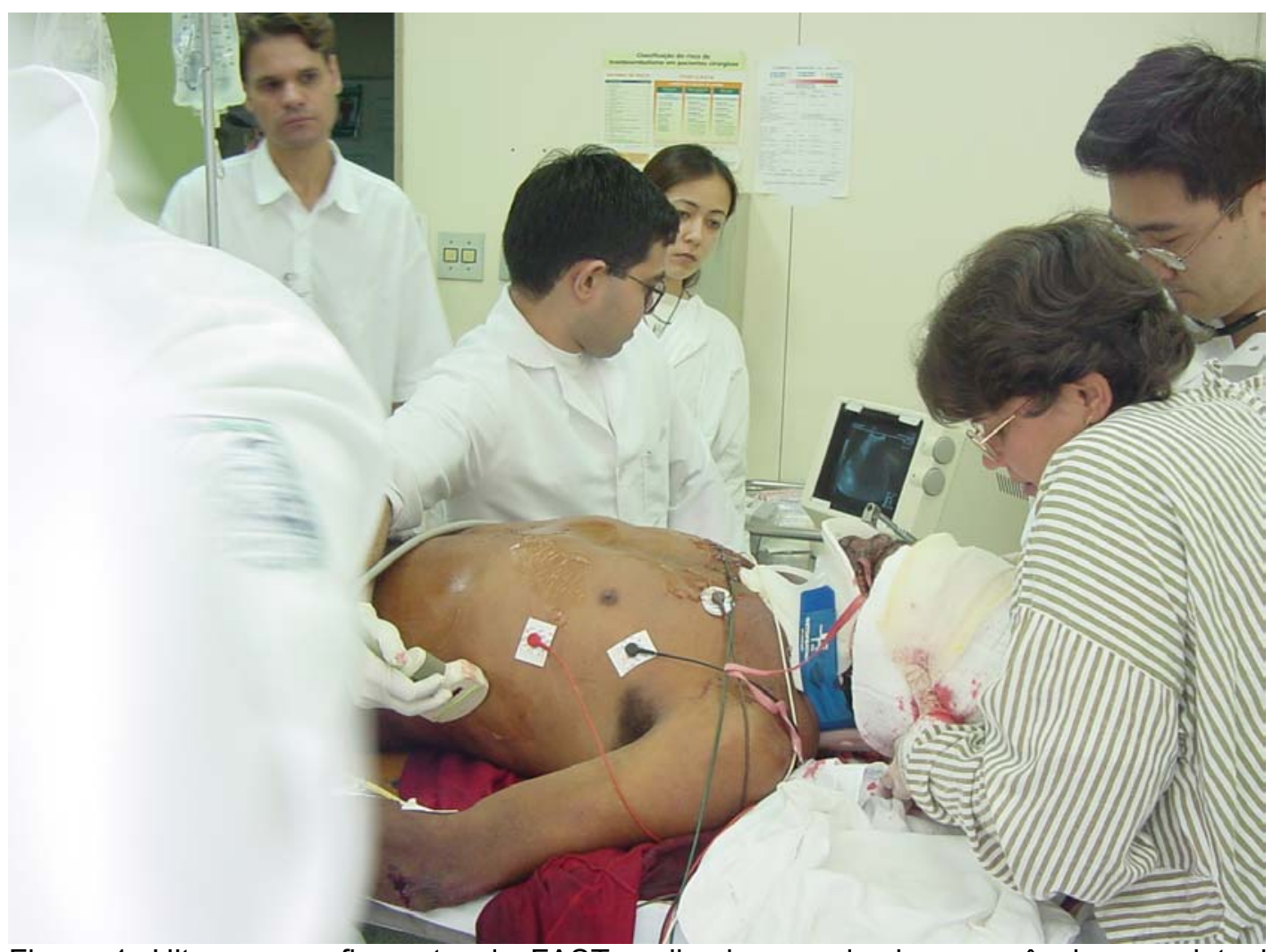

Figura 1: Ultra-sonografia protocolo FAST realizada na sala de emergência, em sintonia com as manobras de atendimento inicial hospitalar

A sensibilidade para a detecção de líquido livre intraperitoneal é de aproximadamente $71 \%$ para $10 \mathrm{ml}$ e $100 \%$ para $50 \mathrm{ml}$ (Paajanen et al. 1999); sendo esse o principal objetivo do exame; porém para a detecção de lesões de órgãos parenquimatosos a sensibilidade é baixa. Assim, a inferência de lesão de órgão parenquimatoso é baixa, porém quando detectada apresenta bom valor preditivo positivo, em geral subestimada em intensidade quando comparada à tomografia computadorizada. De uma maneira geral, o desempenho da ultra-sonografia na detecção de líquido ou lesão parenquimatosa relatada na literatura, em uma metanálise mostrou sensibilidade de 78,9\% e especificidade de 99,2\% (Stengel et al. 2005).

Os resultados falso-positivos de líquido livre correspondente a hemoperitônio correspondem a urinomas, biliomas, ascite e quiloperitônio, 
menos freqüentes, porém possíveis num contexto de trauma. Vale ressaltar que estes diagnósticos diferenciais também podem ser de difícil distinção à tomografia computadorizada, ainda se houver pequenos graus de hemoperitônio associados (McGahan et al. 2002).

Desta forma, a ultra-sonografia abdominal (FAST) torna-se um bom método para indicação dos pacientes que poderiam ser submetidos à tomografia computadorizada, pois já seleciona uma parte dos pacientes com maior potencial de lesão abdominal, quer seja pela presença de líquido livre, que pode corresponder a hemoperitônio, quer seja pela detecção de lesão de órgão parenquimatoso (Rose et al. 2001).

Em certos casos, não infreqüentes, mesmo o exame inicial sendo negativo, indicando ausência de líquido livre ou lesão de órgão parenquimatoso, persiste a dúvida sobre a existência de lesão intraabdominal, indicado pela presença de dor abdominal, rigidez abdominal ao exame, hematúria, instabilidade hemodinâmica ou outros achados associados, como fraturas ósseas.

Estes casos são os que mais geram dúvidas em relação à conduta a ser tomada, sendo muitas decisões resolvidas pela somatória dos achados com a evolução e aspecto do paciente, podendo variar desde a repetição da ultra-sonografia, a realização de tomografia computadorizada à laparotomia exploradora, que têm resultados bastante variados, demonstrando desde a inexistência até a presença de lesões intra-abdominais importantes (Liu et al. 1993). 
Desta forma é necessário que se estabeleçam os parâmetros reais de sensibilidade e especificidade do exame ultra-sonográfico abdominal de emergência focado (FAST) no nosso meio, permitindo estabelecer os índices de valor preditivo positivo e valor preditivo negativo. Desta forma, teremos critérios mais adequados para a indicação da tomografia computadorizada, racionalizando o seu uso e adequando o risco/benefício.

O atendimento ao politraumatismo tornou-se, assim, importante no intuito de garantir melhor prognóstico e sobrevida dos pacientes, alocando recursos para atendimento específico em nível pré-hospitalar - os serviços de resgate - e hospitalar - os centros de traumatismo. A estrutura de atendimento inicial envolve equipes multiprofissionais, bem como multiespecialista, tratando-se dos médicos, incluindo neste caso o radiologista nos últimos anos (Chiquito 1996).

Desta forma, podemos considerar o número de eventos traumáticos, como demanda e o atendimento em nível hospitalar e pré-hospitalar, como oferta. A solução da equação que equilibra oferta e demanda pode ser dimensionada de diversas maneiras, sendo a mais eficiente agindo pelos dois lados: a da demanda, que não é o escopo deste trabalho e depende de medidas governamentais legais e a da oferta, cuja eficiência passa pelo uso dos recursos existentes, aproveitando-se de maneira adequada um modelo preestabelecido e consagrado pelo uso, cujo enfoque quanto à racionalização da utilização dos métodos de imagem, em particular a ultrasonografia e a tomografia computadorizada (Arrillaga et al. 1999). 
2. OBJETIVOS 
Os objetivos deste trabalho são:

1. Avaliar através de estudo prospectivo, a eficácia da ultra-sonografia na avaliação inicial do doente vítima de trauma abdominal fechado para a detecção de lesões intra-abdominais

2. Avaliar através de estudo prospectivo, a eficácia da ultra-sonografia na avaliação inicial do doente vítima de trauma abdominal fechado para a detecção de lesões de órgãos parenquimatosos intraabdominais

3. Verificar se a presença de lesão intra-abdominal apresenta correlação com a presença de líquido intra-peritoneal, na avaliação com a tomografia computadorizada

4. Avaliar a possibilidade de triagem de pacientes vítimas de trauma abdominal fechado através da ultra-sonografia, como suporte para avaliação e tomada de decisões clínicas 


\section{CASUÍSTICA E MÉTODOS}




\subsection{Casuística}

Foram incluídos neste estudo todos os pacientes com mais de 18 anos atendidos no Pronto-Socorro do Hospital das Clínicas no período de 28 de fevereiro de 2006 a 28 de fevereiro de 2007 , vítimas de trauma abdominal fechado e encaminhados diretamente ao serviço pelo Corpo de Bombeiros ou por terceiros.

A pesquisa seguiu as orientações do comitê de ética local com a aprovação do CAPPesq da Diretoria Clínica do HCFMUSP. Todos os pacientes ou responsáveis foram informados e foi obtido consentimento destes, com a assinatura do Termo de Consentimento Livre e Esclarecido.

Estes pacientes foram seguidos na evolução quanto a alta em até 24 horas, alta para outro serviço (Ortopedia) e internação.

Foram realizadas consecutivamente a ultra-sonografia (US) dirigida para trauma (FAST) e tomografia computadorizada (TC). 
Critérios de inclusão:

1. vítima de trauma abdominal fechado;

2. necessitavam avaliação abdominal;

3. concordaram em participar do estudo;

4. realização de ultra-sonografia e tomografia computadorizada e

5. acompanhamento e evolução possível.

Critérios de exclusão:

1. pacientes encaminhados por outro serviço;

2. pacientes menores de idade;

3. pacientes gestantes detectadas à ultra-sonografia ou suspeição de gestação;

4. pacientes que não realizaram a ultra-sonografia e tomografia;

5. pacientes que não concordaram em realizar o estudo;

6. ausência do registro adequado dos exames ou da evolução.

De um total de 826 pacientes atendidos inicialmente por traumatismo abdominal fechado no período pela equipe do Pronto-Socorro foram incluídos neste estudo 163. Dos 663 pacientes excluídos, $470(70,9 \%)$ foram pela não realização de um dos exames, 95 (14,3\%) pela ausência do registro adequado dos exames ou o seu seguimento, $67(10,1 \%)$ pela ausência na concordância com o estudo e 31 (4,7\%) pelas características 
populacionais.

Nos pacientes excluídos, não houve prejuízo ao tratamento e as condutas foram tomadas de acordo com as indicações da equipe cirúrgica e por vezes incluía tomografia computadorizada ou intervenção cirúrgica.

\subsection{Metodologia}

\subsubsection{Ultra-sonografia}

O exame ultra-sonográfico foi realizado durante o atendimento inicial ao paciente, na sala de emergência, utilizando o equipamento de ultrasonografia Toshiba modelo SSA-240 Tosbee ${ }^{\circledR}$ (Toshiba Corporation, Tóquio, Japão), em tempo real, modo $B$, com transdutor convexo com freqüência de $3,5 \mathrm{MHz}$.

O exame foi realizado por um dos membros de plantão da equipe de radiologia do pronto-socorro, do nível do $1^{\circ}$ ano ao $4^{\circ}$ ano de residência médica ou pelo médico-assistente.

Utilizado o protocolo padrão FAST em seis espaços (Nunes et al., 2001), consistindo na avaliação do pericárdio, dos espaço hepatorrenal e espaço esplenorrenal, das cavidades pleurais e da pelve, para a pesquisa de líquido livre e eventuais lesões de víscera parenquimatosa detectadas na 
varredura (Figura 2s Figura 2, Figura 3 e 4).

Anotados os tempos de início e término do exame, a experiência do examinador e a presença de líquido livre mensurada no maior eixo ânteroposterior em cada um dos sítios. Também foi anotado o volume de repleção vesical, se sondada ou não.

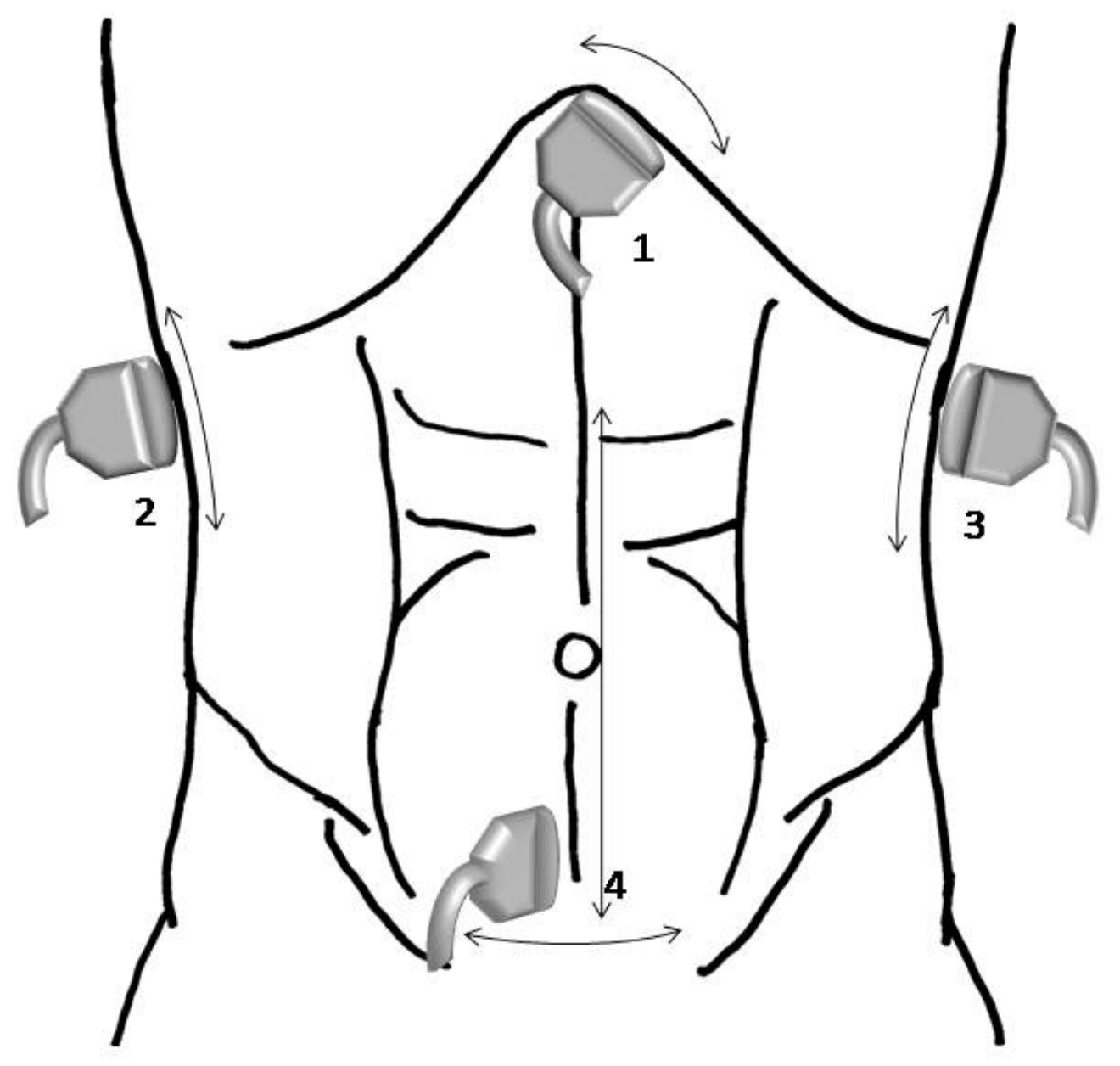

Figura 2 - Protocolo de quatro quadrantes do FAST compreendendo janela pericárdica (1), espaço hepatorrenal (2), espaço esplenorrenal (3) e pelve (4) 


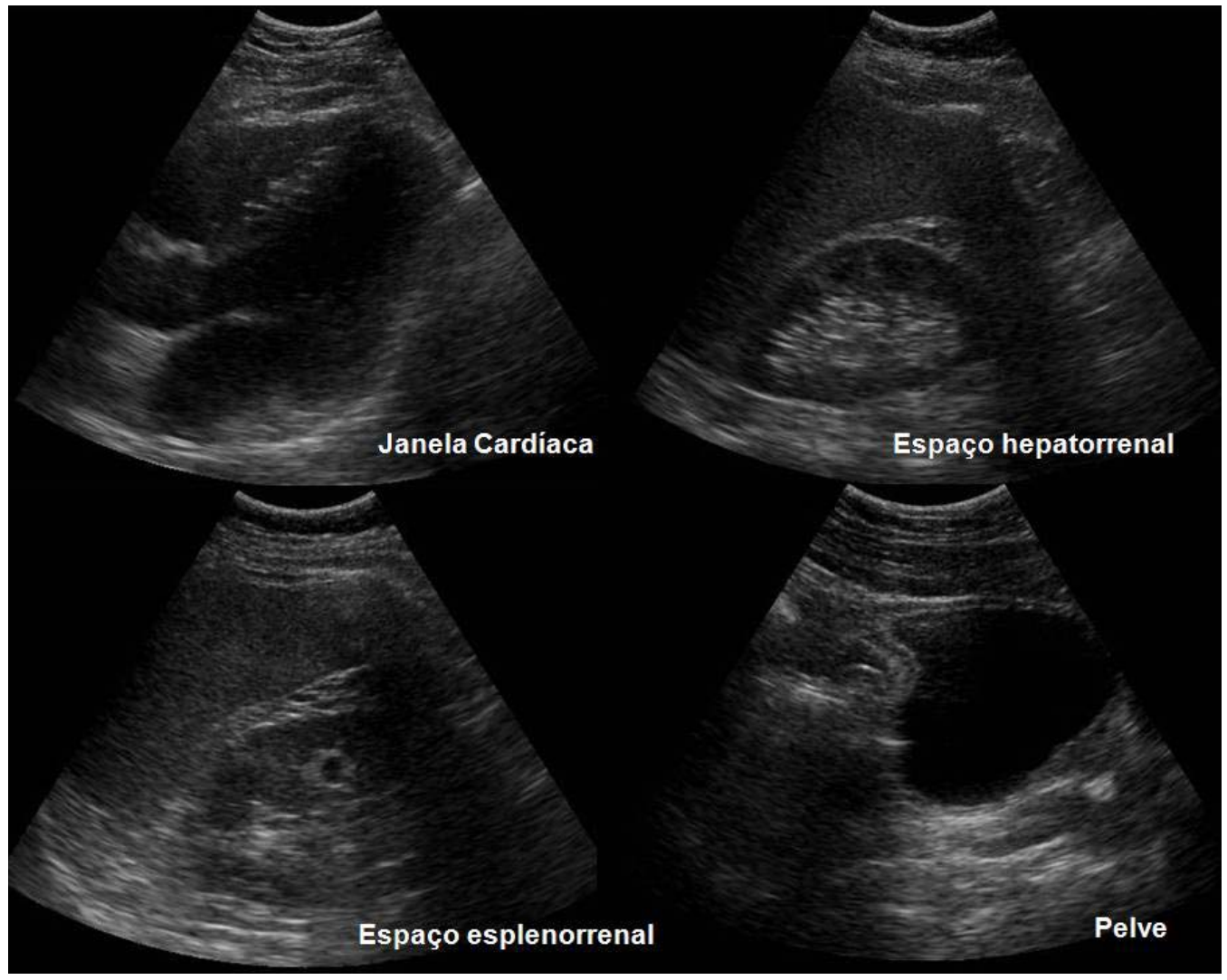

Figura 3 Imagens ultra-sonográficas dos quatro quadrantes do exame

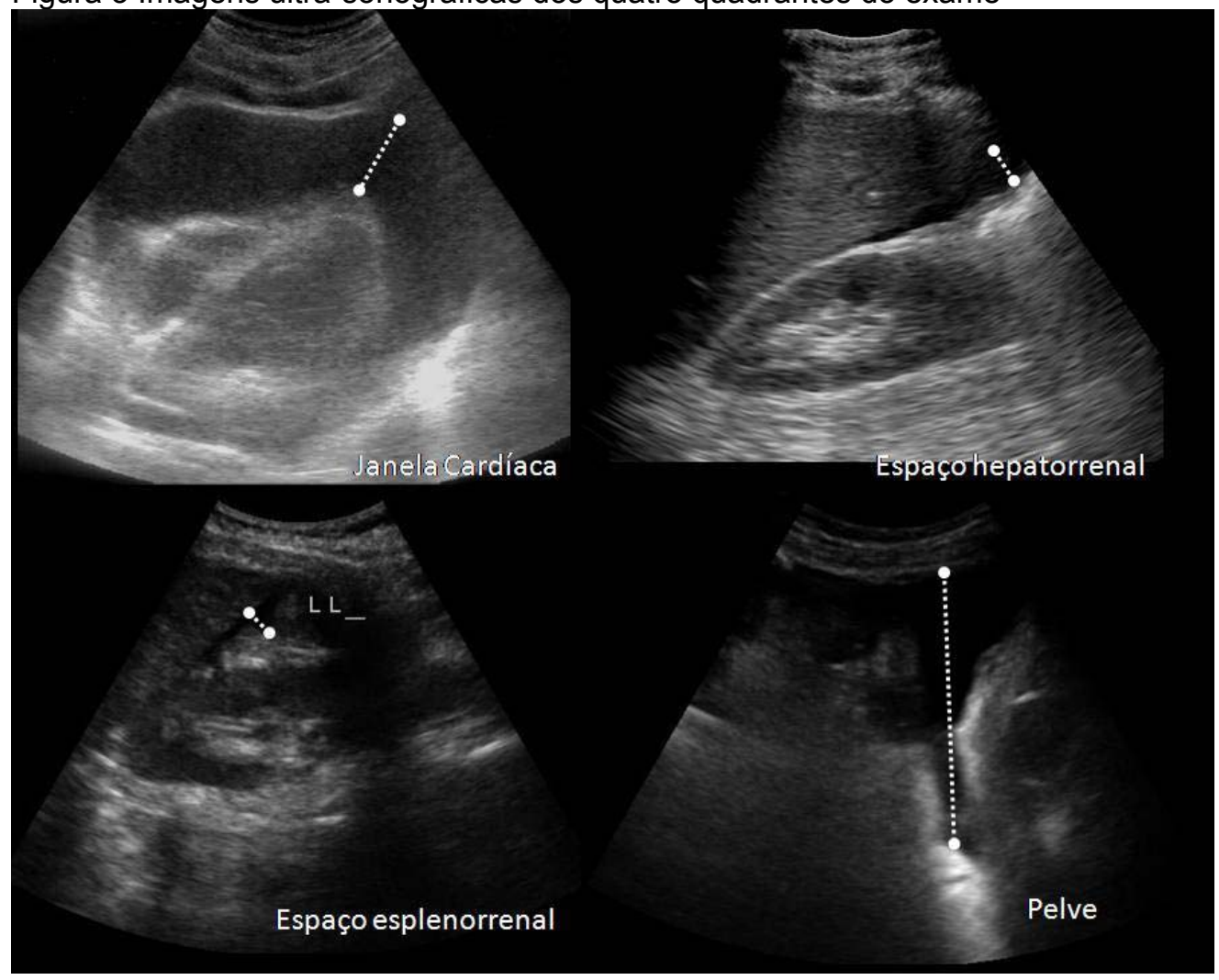

Figura 4 Imagens ultra-sonográficas dos quatro quadrantes do exame evidenciando líquido livre. 


\subsubsection{Tomografia computadorizada}

A tomografia computadorizada foi realizada após a ultra-sonografia inicial, no menor tempo disponível, sem interferir na conduta habitual da equipe cirúrgica, utilizando-se o equipamento helicoidal com tecnologia multidector de 8 canais General Eletric modelo "Lightspeed® Ultra" (GE Medical Systems, Milwaukee, WI, EUA), dedicado do serviço de Radiologia de Emergências do Pronto Socorro do Hospital das Clínicas.

Os exames foram realizados utilizando-se contraste por via oral e por via endovenosa.

O contraste por via oral consistiu de 4 copos de $150 \mathrm{ml}$ (total $600 \mathrm{ml}$ ) de solução de contraste iodado diluído, composto por $50 \mathrm{ml}$ de contraste iônico de alta osmolaridade loxitalamato 300 mg/ml de lodo (Telebrix $30 \circledR$, Guerbet Produtos Radiológicos LTDA, RJ) diluídos em 1000 ml de água, para pacientes conscientes e de $525 \mathrm{ml}$ de uma solução constituída $25 \mathrm{ml}$ desse mesmo contraste diluídos em $500 \mathrm{ml}$ de soro fisiológico para os pacientes inconscientes via sonda nasogástrica.

Ocasionalmente não foi utilizado contraste por via oral quando o paciente estava muito rebaixado e também impossibilitado de ser sondado em função de trauma facial.

O contraste por via endovenosa foi administrado na dose de $2 \mathrm{ml} / \mathrm{kg}$, respeitando-se os volumes mínimo de $100 \mathrm{ml}$ e máximo de $140 \mathrm{ml}$, de 
solução não-iônica e de baixa osmolaridade lobitridol $300 \mathrm{mg} / \mathrm{ml}$ de lodo (Henetix 30®, Guerbet Guerbet Produtos Radiológicos LTDA, RJ) utilizandose de bomba injetora Injectron ${ }^{\circledR}$ 82CT (Medtron AG, Saarbrücken, Alemanha) com velocidade de infusão $3 \mathrm{ml} / \mathrm{s}$.

As imagens foram adquiridas na fase pré-contraste endovenoso e após a injeção do meio de contraste endovenoso durante as fases arterial, portal e excretora (correspondendo respectivamente ao início da aquisição das imagens a 30, 60 e 300 segundos após o início da injeção endovenosa).

Os parâmetros de aquisição foram: configuração de detectores com 8 fileiras de 2,5 mm, feixe de colimação de $20 \mathrm{~mm}$, velocidade de translação da mesa de $27 \mathrm{~mm} /$ rotação (pitch 1,35:1), tempo de rotação do tubo de 0,8 $\mathrm{s}$, voltagem na ampola de $120 \mathrm{kV}$ e mA automático, variável de acordo com a espessura do paciente, com mínimo de 160 mA e máximo de 400 mA e índice de ruído de 15,13 (AutomA® GE Medical Systems, Milwaukee, WI, EUA). As imagens foram reconstruídas com 3,75 $\mathrm{mm}$ de espessura e com intervalo de $1,8 \mathrm{~mm}$.

A análise das imagens foi realizada em workstation dedicada com software Advantage ADW4.2 (GE Medical Systems, Milwaukee, WI, EUA) pelo médico radiologista assistente de plantão. 
3.2.3. Interpretação dos achados

A ultra-sonografia foi considerada positiva quando foi detectado líquido livre intraperitoneal ou sinais sugestivos de lesão de órgão intraparenquimatoso, pneumoperitônio ou hematoma retroperitoneal e negativo o resultado quando não se detectou nenhum destes achados.

A tomografia computadorizada foi considerada positiva quando o exame detectava lesão de víscera parenquimatosa ou oca, hematoma de mesentério, hematoma retroperitoneal e líquido livre. A presença isolada de líquido livre, sem outra lesão intra-abdominal associada foi interpretada como negativo. Anotados quanto ao líquido livre a espessura ânteroposterior, para adequada correlação ultra-sonográfica e quanto às lesões de vísceras parenquimatosas as dimensões, se única ou múltipla e a profundidade da lesão.

Os pacientes foram seguidos e foram divididos em grupos de acordo com a evolução: alta (quando liberados em 24 horas), internação (quando permaneceram por mais de 24 horas por motivos cirúrgicos gerais), internação por outros motivos (quando foram transferidos para outro setor, notadamente para o Instituto de Ortopedia) e óbito (por qualquer razão). 
3.2.4. Registro e análise dos dados

Os dados foram registrados em formulários próprios e tabulados em banco de dados baseado em Microsoft Access 2003 (Microsoft Corporation, Redmond, WA, EUA) sendo posteriormente extraídas tabelas que foram analisadas em programa de análise estatística SPSS for Windows 12.0 (SPSS Inc, Chicago, II, EUA).

Foi utilizado o teste do qui-quadrado e a análise de correlação de Spearman para o processamento das tabelas, adotando-se o nível de significância de 0,05 , sendo que níveis descritivos (p) inferiores a esse valor foram considerados significativos.

Foram obtidos valores de:

- sensibilidade, que corresponde ao percentual de verdadeiros positivos do método testado dentre todos os pacientes positivos (comparado ao método de referência),

- especificidade, que corresponde ao percentual de verdadeiros negativos dentre todos os pacientes negativos do método testado dentre todos os pacientes positivos (comparado ao método de referência),

- acurácia, que corresponde ao percentual dos resultados iguais entre o método testado e de referência,

- prevalência, que corresponde ao percentual de eventos positivos pelo método de referência dentro da amostra 
populacional total pesquisada,

- valor preditivo positivo, que corresponde à probabilidade do realmente existir o evento medido quando o resultado obtido pelo método testado for positivo,

- valor preditivo negativo, que corresponde à probabilidade de não existir o evento medido quando o resultado obtido pelo método testado for negativo. 


\section{RESULTADOS}




\subsection{Características dos pacientes}

Dos 163 que foram incluídos no estudo por atenderem os critérios de seleção 135 eram do sexo masculino $(82,8 \%)$ e 28 eram do sexo feminino $(17,2 \%)$.

A idade mínima foi de 18 anos, a máxima de 97 anos, a média de idade de 35,96 anos (desvio-padrão de 14,06 anos), mediana de 32 anos e moda de 25 anos. Separando-se pela faixa etária por décadas, observa-se que a maior parte dos pacientes se encontra entre os 20 e 29 anos e entre os 30 e 39 anos, segundo a tabela 1.

Tabela 1- Distribuição de casos de acordo com a faixa etária

\begin{tabular}{c|cc}
\hline Faixa etária (anos) & Pacientes & $\%$ \\
\hline Até 20 & 17 & 10,4 \\
$20-29$ & 48 & 29,5 \\
$30-39$ & 44 & 27,0 \\
$40-49$ & 31 & 19,0 \\
$50-59$ & 13 & 8,0 \\
$60-69$ & 5 & 3,1 \\
$70-79$ & 4 & 2,5 \\
Acima de 79 & 1 & 0,6 \\
\hline Total & 163 & 100,00 \\
\hline
\end{tabular}

A causa do trauma foi predominantemente decorrente de trânsito $(73,0 \%)$, sendo queda $(20,2 \%)$, agressão $(4,3 \%)$ e compressão $2,5 \%)$ as outras causas, detalhadas na tabela 2. 
Tabela 2 - Distribuição de casos de acordo com as causas de trauma

\begin{tabular}{l|cc}
\hline \multicolumn{1}{c|}{ Causa } & Pacientes & $\%$ \\
\hline Atropelamento & 47 & 28,8 \\
Moto & 41 & 25,2 \\
Auto & 28 & 17,2 \\
Ônibus & 1 & 0,6 \\
Bicicleta & 2 & 1,2 \\
Agressão & 7 & 4,3 \\
Queda & 33 & 20,2 \\
Compressão & 4 & 2,5 \\
\hline \multicolumn{1}{c}{ Total } & 163 & 100,00 \\
\hline
\end{tabular}

Os pacientes foram trazidos para o Pronto-Socorro num tempo mínimo de 15 minutos e máximo de 480 minutos, com média de 51,93 minutos, em relação ao trauma. Estratificando-os em quartos de hora, a maior parte dos pacientes (72\%) foi trazida entre 15 e 45 minutos (47\% entre $15-30$ minutos e $25 \%$ entre $30-45$ minutos).

Quanto ao quadro clínico, a pressão arterial sistólica média aferida no hospital foi de $125,71 \mathrm{mmHg}$ (desvio-padrão de $23,41 \mathrm{mmHg}$ ), sendo que 96,3\% apresentavam pressão sistólica acima de $90 \mathrm{mmHg}$; a freqüência cardíaca variou entre 15 e 180 batimentos por minuto, sendo a média de 93,06 batimentos por minuto (desvio-padrão de 20,2) e a mediana e moda 90 batimentos por minuto; a Escala de Coma de Glasgow (GCS) variou de 3 a 15 , sendo a média de 13 e mediana e moda de 15. A maior parte dos pacientes $(71,2 \%)$ apresentava GCS de 14 ou 15 , conforme tabela 3. 
Tabela 3 - Distribuição de casos de acordo com a Escala de Coma de Glasgow (GCS)

\begin{tabular}{c|cc}
\hline GCS & Pacientes & $\%$ \\
\hline 3 & 9 & 5,5 \\
$4-5$ & 5 & 3,1 \\
$6-8$ & 15 & 9,2 \\
$9-12$ & 16 & 9,8 \\
$13-15$ & 118 & 72,4 \\
\hline Total & 163 & 100,00 \\
\hline
\end{tabular}

O índice de trauma revisado não pode ser calculado pela irregularidade da obtenção do dado de freqüência respiratória necessária para este cálculo.

\subsection{Exames}

O tempo de realização da ultra-sonografia oscilou entre um mínimo de 1 minuto ao máximo de 14 minutos, com tempo médio de realização de 5,16 minutos (desvio-padrão de 2,49 minutos), mediana e moda de 5 minutos.

O intervalo entre os exames de ultra-sonografia e tomografia computadorizada variou entre 15 e 420 minutos, com tempo médio de 155,27 minutos (desvio-padrão de 63,87 minutos), mediana de 150 minutos e moda de 120 minutos.

Dos 163 pacientes avaliados, 31 (19,0\%) apresentaram ultrasonografia positiva e $132(81,0 \%)$ apresentaram ultra-sonografia negativa. Do total de pacientes, à tomografia computadorizada, $33(20,2 \%)$ pacientes 
apresentaram exame positivo e 130 apresentaram tomografia negativa $(79,8 \%)$.

Não houve diferença quanto à positividade ou negatividade da ultrasonografia em relação à experiência do examinador, conforme tabela 4.

Tabela 4 - Distribuição de casos de acordo com a experiência do examinador

\begin{tabular}{|c|c|c|c|c|c|c|}
\hline & R1 & $\mathrm{R} 2$ & R3 & R4 & Assistente & Total \\
\hline $\begin{array}{l}\text { US Positiva } \\
\%\end{array}$ & $\begin{array}{l}5 \\
3,1 \%\end{array}$ & $\begin{array}{l}10 \\
6,1 \%\end{array}$ & $\begin{array}{l}12 \\
7,4 \%\end{array}$ & $\begin{array}{l}0 \\
0,0 \%\end{array}$ & $\begin{array}{l}5 \\
3,1 \%\end{array}$ & $\begin{array}{l}31 \\
19,7 \%\end{array}$ \\
\hline $\begin{array}{l}\text { US Negativa } \\
\%\end{array}$ & $\begin{array}{l}32 \\
19,6 \%\end{array}$ & $\begin{array}{l}52 \\
31,9 \% \\
\end{array}$ & $\begin{array}{l}32 \\
19,6 \% \\
\end{array}$ & $\begin{array}{l}1 \\
0,6 \% \\
\end{array}$ & $\begin{array}{l}14 \\
8,6 \% \\
\end{array}$ & $\begin{array}{l}132 \\
80,3 \% \\
\end{array}$ \\
\hline $\begin{array}{l}\text { Total } \\
\%\end{array}$ & $\begin{array}{l}37 \\
22,7 \%\end{array}$ & $\begin{array}{l}62 \\
38,0 \%\end{array}$ & $\begin{array}{l}44 \\
27,0 \% \\
\end{array}$ & $\begin{array}{l}1 \\
0,6 \% \\
\end{array}$ & $\begin{array}{l}19 \\
11,7 \% \\
\end{array}$ & $\begin{array}{l}163 \\
100 \% \\
\end{array}$ \\
\hline
\end{tabular}

Dos 31 casos ultra-sonográficos positivos, $24 \quad(77,4 \%)$ foram confirmados como positivos pela tomografia computadorizada e $7(22,6 \%)$ foram relatados como negativos pela tomografia computadorizada. Dos 132 casos ultra-sonográficos negativos, $123(93,2 \%)$ foram confirmados como negativos e $9(6,8 \%)$ foram relatados como positivos pela tomografia computadorizada, conforme tabela 5 .

Tabela 5 - Distribuição de casos de acordo com os resultados de US e TC

\begin{tabular}{l|lll}
\hline & TC Positiva & TC Negativa & Total \\
\hline US Positiva & 24 & 7 & 31 \\
US Negativa & 9 & 123 & 132 \\
\hline Total & 33 & 130 & 163 \\
\hline
\end{tabular}


Esses dados indicam que a ultra-sonografia para detecção de lesões intra-abdominais apresenta uma sensibilidade de $72,7 \%$ e especificidade de $94,6 \%$, com acurácia de $90,2 \%$, em um grupo de pacientes cuja prevalência de lesão é de $20,2 \%$. O valor preditivo positivo é de $77,4 \%$ e o valor preditivo negativo é de $93,2 \%$.

Realizando-se nova análise, agora se considerando positiva também os exames tomográficos que apesar de apresentarem líquido livre, não apresentavam outros sinais de lesão de víscera parenquimatosa, víscera oca, mesentérica ou retroperitoneal e que foram previamente considerados como negativos, temos 29 casos positivos e 2 negativos dentre os pacientes com ultra-sonografia positiva e 16 casos positivos e 116 casos negativos dentre os pacientes com ultra-sonografia negativa, conforme tabela 6 .

Tabela 6 - Redistribuição de casos com correção do resultado da tomografia computadorizada

\begin{tabular}{l|lll}
\hline & TC Positiva* & TC Negativa* & Total \\
\hline US Positiva & 29 & 2 & 31 \\
US Negativa & 16 & 116 & 132 \\
\hline Total & 45 & 118 & 163 \\
\hline \multicolumn{4}{r}{$\begin{array}{r}\text { p }<0,001 \\
\text { *considerando-se positiva a presença de líquido à TC em } \\
\text { quaisquer circunstâncias }\end{array}$}
\end{tabular}

Esses dados representam que a ultra-sonografia na detecção de líquido livre tem uma sensibilidade de $64,4 \%$, especificidade de $98,3 \%$, com acurácia de $88,9 \%$ em um grupo de pacientes cuja prevalência é de $27,6 \%$. O valor preditivo positivo de $93,5 \%$ e valor preditivo negativo de $87,9 \%$. 


\subsection{Evolução}

Quanto à evolução, dos 31 casos com resultado ultra-sonográfico positivo, 5 receberam alta, 21 foram internados e 5 sofreram óbito e dos 132 com resultado ultra-sonográfico negativo, 78 receberam alta, 23 foram internados, 21 foram transferidos para outro serviço e 10 sofreram óbito, conforme tabela 7.

Tabela 7 - Distribuição de casos de acordo com a evolução, em relação à US

\begin{tabular}{l|lllll}
\hline & Alta & Internação & Transferência & Óbito & Total \\
\hline US & 5 & 20 & 0 & 6 & 31 \\
positiva & $(16,1 \%)$ & $(64,5 \%)$ & $(0,0 \%)$ & $(19,4 \%)$ & $(100,0 \%)$ \\
US & 78 & 24 & 21 & 9 & 132 \\
negativa & $(59,1 \%)$ & $(18,2 \%)$ & $(15,9 \%)$ & $(6,8 \%)$ & $(100,0 \%)$ \\
\hline Total & 83 & 44 & 21 & 15 & 163 \\
\hline
\end{tabular}

Se relacionado quanto à necessidade de cirurgia, dos 31 pacientes com ultra-sonografia positiva, $18(58,1 \%)$ necessitaram cirurgia e $13(41,9 \%)$ não necessitaram cirurgia e dos 132 pacientes com exame negativo, 8 necessitaram cirurgia (6,1\%) e 124 (93,9\%) não necessitaram cirurgia, conforme tabela 8 .

Tabela 8- Necessidade de cirurgia em relação à US

\begin{tabular}{l|lll}
\hline & Cirurgia & Não Cirurgia & Total \\
\hline US Positiva & $18(58,1 \%)$ & $13(41,9 \%)$ & 31 \\
US Negativa & $8(6,1 \%)$ & $124(93,9 \%)$ & 132 \\
\hline Total & 26 & 137 & 163 \\
\hline
\end{tabular}


Esses dados representam, quanto à necessidade de cirurgia segundo o resultado da ultra-sonografia, acurácia de $87,1 \%$, valor preditivo positivo de $58,1 \%$ e valor preditivo negativo de $93,9 \%$.

Considerando-se a evolução em relação ao resultado da tomografia computadorizada, dos 33 pacientes com resultado positivo, 1 (3,0\%) recebeu alta, $27(81,8 \%)$ foram internados, nenhum foi transferido e $5(15,2 \%)$ sofreram óbito; dos 130 pacientes com resultado negativo, 82 (63,1\%) receberam alta, $17(13,1 \%)$ foram internados, $21(16,2 \%)$ foram transferidos e $10(7,7 \%)$ sofreram óbito, conforme tabela 9 .

Tabela 9 - Distribuição de casos de acordo com a evolução, em relação à TC

\begin{tabular}{l|lllll}
\hline & Alta & Internação & Transferência & Óbito & Total \\
\hline TC & 1 & 27 & 0 & 5 & 33 \\
positiva & $(3,0 \%)$ & $(81,8 \%)$ & & $(15,2 \%)$ & \\
TC & 82 & 17 & $21(16,2 \%)$ & 10 & 130 \\
negativa & $(63,1 \%)$ & $(13,1 \%)$ & & $(7,7 \%)$ & \\
\hline Total & 83 & 44 & 21 & 15 & 163 \\
\hline
\end{tabular}

Se relacionado quanto à necessidade de cirurgia, dos 33 pacientes com tomografia computadorizada positiva, $22(66,7 \%)$ necessitaram cirurgia e $11(33,3 \%)$ não necessitaram cirurgia e dos 130 pacientes com exame negativo, 4 necessitaram cirurgia $(3,1 \%)$ e $126(96,9 \%)$ não necessitaram cirurgia (tabela 10). 
Tabela 10 - Necessidade de cirurgia em relação à TC

\begin{tabular}{l|lll}
\hline & Cirurgia & Não Cirurgia & Total \\
\hline TC Positiva & $22(66,7 \%)$ & $11(33,3 \%)$ & 33 \\
TC Negativa & $4(3,1 \%)$ & $126(96,9 \%)$ & 130 \\
\hline Total & 26 & 137 & 163 \\
\hline
\end{tabular}

Esses dados representam, quanto à necessidade de cirurgia segundo o resultado da tomografia computadorizada, acurácia de $90,8 \%$, valor preditivo positivo de $66,7 \%$ e valor preditivo negativo de $96,7 \%$.

Foram encontradas 7 imagens sugestivas de lesões de víscera parenquimatosa à ultra-sonografia em 7 pacientes com ultra-sonografia positiva $(22,6 \%)$, sendo confirmadas as lesões em 5 deles: duas hepáticas, duas esplênicas e uma renal esquerda.

\subsection{Falso Positivos}

Dos 7 casos em que a ultra-sonografia foi positiva e a tomografia foi negativa (falso positivo), 4 pacientes eram do sexo masculino e 3 eram do sexo feminino, observando-se, quanto ao tipo de trauma 5 originados do trânsito (3 por motocicleta, 1 por automóvel e 1 atropelamento), 1 agressão e 1 queda. Havia rebaixamento no nível de consciência em 2 pacientes (GCS de 7 e 10) estando os outros conscientes. Todos receberam quantidades variáveis de soro até o momento do exame (3 não recebendo SF, $500 \mathrm{ml}$, 
$1000 \mathrm{ml}, 3000 \mathrm{ml}$ e $3500 \mathrm{ml}$ os outros). A bexiga estava cheia em 4 pacientes e vazia nos outros 3 .

Desses 7 pacientes, 6 apresentaram líquido à ultra-sonografia na pelve, variando entre $0,5 \mathrm{~cm}$ e $2,5 \mathrm{~cm}$ e destes, 2 também apresentando líquido no espaço hepatorrenal medindo $0,2 \mathrm{~cm}$ (e 2,0 cm na pelve) em um caso e $1,5 \mathrm{~cm}$ (e $1,0 \mathrm{~cm}$ na pelve) no outro; no único paciente que não apresentava líquido livre o exame foi considerado positivo pela presença de imagem interpretada com lesão renal. A experiência do observador foi: 1 residente do $1^{\circ}$ ano (20\% dos exames positivos deste grupo), 1 residente do $2^{\circ}$ ano (10\% dos exames positivos deste grupo), 3 residentes do $3^{\circ}$ ano ( $25 \%$ dos exames positivos deste grupo) e 2 assistentes (40\% dos exames positivos deste grupo).

Ressalta-se nesses, a presença de líquido também na tomografia computadorizada em 5 dos 7 pacientes, porém sem sinais de lesão de víscera ou lesão intraperitoneal, todos eles com líquido na pelve, variando de $1,0 \mathrm{~cm}$ a $5,0 \mathrm{~cm}$ e destes, 1 deles com líquido no espaço hepatorrenal e 2 com líquido no espaço esplenorrenal. Dos 7 pacientes, 1 apresentava fratura de bacia, 1 apresentava fratura de costelas à esquerda (e também líquido no espaço esplenorrenal). Nenhum dos pacientes foi submetido à cirurgia, observando-se 4 altas, 1 internação e 2 óbitos, por motivos neurológicos (justamente os rebaixados). 


\subsection{Falso Negativos}

Dos 9 casos em que a ultra-sonografia foi negativa e a tomografia foi positiva (falso negativo) 7 pacientes eram do sexo masculino e 2 eram do sexo feminino, observando-se, quanto ao tipo de trauma 7 originados do trânsito (1 por motocicleta, 3 por automóvel e 3 atropelamento), e 2 quedas. Havia rebaixamento no nível de consciência em 3 pacientes (GCS de 8, 10 e 12) estando os outros conscientes (2 com GCS de 15 e 4 com GCS de 14). Todos receberam quantidades variáveis de soro até o momento do exame (1 não recebendo SF, 4 recebendo $500 \mathrm{ml}$, e os outros $1000 \mathrm{ml}, 2$ recebendo $2000 \mathrm{ml}$ e $4000 \mathrm{ml}$ ). A bexiga estava cheia em 6 pacientes e vazia em 3.

Nesses 9 pacientes, 4 apresentaram à tomografia computadorizada líquido livre. No primeiro havia líquido na pelve, no espaço hepatorrenal $(0,5$ cm em cada) e esplenorrenal $(0,4 \mathrm{~cm})$, além de múltiplas lacerações esplênicas de até $1,0 \mathrm{~cm}$ de profundidade e contusão adrenal esquerda, além de densificação peripancreática. No segundo havia líquido no espaço hepatorrenal e esplenorrenal $(0,5 \mathrm{~cm})$ além de hematoma perirrenal e hematoma de mesentério. No terceiro paciente, havia líquido no espaço hepatorrenal $(1,3 \mathrm{~cm})$, associado a hematoma adrenal direito. No quarto paciente, havia líquido no espaço esplenorrenal $(0,8 \mathrm{~cm})$ além de lacerações esplênicas de até $1,5 \mathrm{~cm}$. Os outros 5 pacientes não apresentavam líquido livre, porém o primeiro destes apresentava laceração hepática múltipla de até $1,0 \mathrm{~cm}$, o segundo apresentava lacerações hepáticas múltiplas com até 
$5,0 \mathrm{~cm}$ de profundidade e hematoma adrenal direita, o terceiro apresentava contusão esplênica e hematoma de retroperitônio, o quarto apresentava contusão hepática de $1,0 \mathrm{~cm}$ e o quinto apresentava apenas hematoma de retroperitônio.

Dentre outras lesões observadas nesses pacientes, fratura de costelas à esquerda foi encontrada em 5 pacientes e também à direita em 1 destes, fraturas isoladas à direita não foram observadas nesse grupo; fraturas de coluna lombar foram encontradas em 2 pacientes e fraturas na bacia em 4 pacientes.

A experiência do observador foi: 3 residentes do $1^{\circ}$ ano $(9 \%$ dos exames negativos deste grupo), 3 residentes do $2^{\circ}$ ano $(6 \% \%$ dos exames negativos deste grupo) e 1 residente do $3^{\circ}$ ano (3\%).

4 dos 9 pacientes foram submetidos à cirurgia, observando-se 8 internações e 1 óbito.

4.6. Líquido livre

\subsubsection{Ultra-sonografia}

Dos 31 casos de ultra-sonografia positiva, 4 não apresentavam líquido livre e 27 apresentavam líquido livre, notando-se correlação total (isto é, 
líquido nos mesmos setores) deste achado com a tomografia em 13 casos e correlação parcial (isto é, líquido em setores distintos ou não detectado em alguns setores) em 14.

Nesses 27 casos em que foi achado líquido livre à ultra-sonografia, 20 (74,1\%) apresentavam líquido no espaço hepatorrenal, $18(66,7 \%)$ apresentavam líquido na pelve e $10(37,0 \%)$ apresentavam líquido no espaço esplenorrenal. Estratificando-se estes dados, 6 (22,2\%) pacientes apresentavam líquido apenas no espaço hepatorrenal, nenhum apresentou líquido apenas no espaço esplenorrenal, 6 (22,2\%) pacientes apresentaram líquido apenas na pelve, $4(14,8 \%)$ pacientes apresentavam líquido no espaço hepatorrenal e na pelve, $1(3,7 \%)$ paciente apresentou líquido no espaço esplenorrenal e na pelve, $3(11,1 \%)$ pacientes apresentavam líquido no espaço hepatorrenal e no espaço esplenorrenal e 7 (25,9\%) pacientes apresentaram líquido nos espaços hepatorrenal, esplenorrenal e na pelve (tabela 11).

Dos 7 casos falso positivos, 6 deles apresentavam líquido; destes 4 apresentavam líquido apenas na pelve, com até $2,5 \mathrm{~cm}$ de espessura e 2 apresentavam líquido no espaço hepatorrenal e na pelve. Desses 7 foi caracterizado líquido também à tomografia computadorizada, porém sem sinais de lesão de víscera parenquimatosa, em 5 deles. 
Tabela 11- Distribuição do achado de líquido na US

\begin{tabular}{l|ll}
\hline Líquido na US & Pacientes & $\%$ \\
\hline Hepatorrenal isolado & 6 & 22,2 \\
Esplenorrenal isolado & 0 & 0 \\
Pelve isolado & 6 & 22,2 \\
Hepatorrenal e pelve & 4 & 14,8 \\
$\begin{array}{l}\text { Esplenorrenal e pelve } \\
\text { Hepatorrenal }\end{array} \quad$ e & 3 & 3,7 \\
$\begin{array}{l}\text { esplenorrenal } \\
\text { Hepatorrenal, }\end{array}$ & 7 & 11,1 \\
esplenorrenal e pelve & & 25,9 \\
\hline Total & 27 & 100,0 \\
\hline
\end{tabular}

Quanto ao volume, 11 dos 27 pacientes com líquido livre apresentavam somatória dos bolsões superior a $3 \mathrm{~cm}$, considerado como volumoso (Huang et al. 1994), sendo todos eles submetidos a cirurgia. Dos 16 restantes com somatória inferior a $3 \mathrm{~cm}, 6(37,5 \%)$ necessitaram intervenção cirúrgica e 10 (62,5\%) foram tratados de maneira conservadora.

Dos 27 pacientes com líquido livre à ultra-sonografia, 4 também apresentaram sinais sugestivos de lesão de víscera parenquimatosa concomitante ao líquido livre, sendo 3 no espaço esplenorrenal e 1 no espaço hepatorrenal.

Ainda dos 31 casos de ultra-sonografia positiva 4 casos não mostraram líquido livre e foram considerados positivos pela suspeita de lesão de víscera parenquimatosa (3 pacientes) ou hematoma retroperitoneal (1 paciente). A tomografia computadorizada confirmou a ausência de líquido em todos, sendo confirmadas as lesões em 2 casos (1 caso de lesão hepática e 1 caso de hematoma retroperitoneal) e não confirmados em outros 2 (1 caso apontando lesão vesical e outro caso sem lesões intraabdominais - falso positivo). 


\subsubsection{Tomografia computadorizada}

Dos 45 pacientes com líquido livre à tomografia computadorizada 27 (60,0\%) pacientes apresentavam líquido no espaço hepatorrenal $23(51,1 \%)$ pacientes apresentavam líquido no espaço esplenorrenal e 28 (62,2\%) pacientes apresentaram líquido na pelve.

Dos 45 casos de tomografia positiva inclusive para líquido livre, 12 não apresentavam lesões intra-abdominais detectáveis. Nestes 12 pacientes $1(8,3 \%)$ paciente apresentou líquido apenas no espaço hepatorrenal, 1 (8,3\%) paciente apresentou líquido apenas no espaço esplenorrenal, 7 $(58,5 \%)$ pacientes apresentaram líquido apenas na pelve, $1(8,3 \%)$ paciente apresentou líquido no espaço hepatorrenal e na pelve, 1 (8,3\%) paciente apresentou líquido no espaço esplenorrenal e na pelve e $1(8,3 \%)$ paciente apresentou líquido nos espaços hepatorrenal e esplenorrenal e na pelve, conforme tabela 12. Dessa forma, nestes pacientes detectou-se a presença de líquido na pelve em 83,4\% dos casos. Ainda destes 12 pacientes, em 5 deles a ultra-sonografia detectou líquido na pelve, em 4 delas no espaço hepatorrenal e na pelve e em 1 deles no espaço esplenorrenal, que à tomografia também apresentava líquido no espaço esplenorrenal além dos outros dois compartimentos, conforme tabela 12. 
Tabela 12 - Distribuição do achado de líquido na TC sem outras lesões intra-abdominais detectáveis

\begin{tabular}{l|ll}
\hline $\begin{array}{l}\text { Líquido na TC sem outras } \\
\text { lesões detectáveis }\end{array}$ & Pacientes & $\%$ \\
\hline Hepatorrenal isolado & 1 & 8,3 \\
Esplenorrenal isolado & 1 & 8,3 \\
Pelve isolado & 7 & 58,5 \\
Hepatorrenal e pelve & 1 & 8,3 \\
Esplenorrenal e pelve & 1 & 8,3 \\
Hepatorrenal e & 0 & 0,0 \\
esplenorrenal & & 8,3 \\
Hepatorrenal, esplenorrenal & 1 & \\
e pelve & & 100,0 \\
\hline Total & 12 & \\
\hline
\end{tabular}

Dos 33 pacientes com lesões intra-abdominais, 8 (24,2\%) não apresentavam líquido livre e $25(75,8 \%)$ apresentavam líquido livre. Destes 25 pacientes com líquido livre $1(4,0 \%)$ paciente apresentou líquido apenas no espaço hepatorrenal, $1(4,0 \%)$ paciente apresentou líquido apenas no espaço esplenorrenal, nenhum paciente apresentou líquido apenas na pelve ou no espaço esplenorrenal e na pelve, $4(16,0 \%)$ pacientes apresentaram líquido no espaço hepatorrenal e na pelve, 6 (24,0\%) pacientes apresentaram líquido nos espaços hepatorrenal e esplenorrenal, 13 (52,0\%) pacientes apresentaram líquido nos espaços hepatorrenal e esplenorrenal e na pelve, conforme tabela 13. 
Tabela 13 - Distribuição do achado de líquido na TC associada a lesões intra-abdominais

\begin{tabular}{l|ll}
\hline Líquido na TC & Pacientes & $\%$ \\
\hline Hepatorrenal isolado & 1 & 4,0 \\
Esplenorrenal isolado & 1 & 4,0 \\
Pelve isolado & 0 & 0 \\
Hepatorrenal e pelve & 4 & 16,0 \\
Esplenorrenal e pelve & 0 & 0,0 \\
Hepatorrenal e & 6 & 24,0 \\
esplenorrenal & & 52,0 \\
Hepatorrenal, & 13 & \\
esplenorrenal e pelve & & 100,0 \\
\hline Total & 25 &
\end{tabular}

Dos 130 pacientes com tomografia computadorizada negativa para lesões abdominais, 12 apresentavam quantidades variáveis de líquido (entre $0,7 \mathrm{~cm}$ e $5,0 \mathrm{~cm}$ ), porém sem evidência de lesão abdominal, sendo $5 \mathrm{com}$ exame ultra-sonográfico positivo e 7 com exame ultra-sonográfico negativo.

Destes, foram encontradas no primeiro grupo 3 pacientes com fraturas em costelas e 1 paciente com fratura na bacia e no segundo grupo 1 paciente com fratura em costelas e 1 paciente com fratura na bacia. No primeiro grupo 2 pacientes tiveram alta e 3 precisaram internação e no segundo grupo 4 tiveram alta, um foi transferido e dois sofreram óbito. Nenhum paciente necessitou ser submetido a cirurgia. 
5.DISCUSSÃO 


\subsection{População}

Quanto à população estudada, os dados obtidos indicam que a amostra de pacientes corresponde às características do grupo de pacientes vítimas de traumatismo normalmente observados na população em geral: adultos jovens do sexo masculino (Birolini 2001).

Também segue a tendência geral a presença de um grande número de vítimas de acidente de trânsito, aproximadamente $73 \%$, destacando-se neste um grande número de vítimas motociclistas, cerca de $25 \%$, a mesma proporção aproximada do número de atropelamentos, cerca de $29 \%$, em acordo com os dados disponíveis pelo Ministério da Saúde, considerando-se as internações hospitalares ao invés dos dados de mortalidade (Ministério da Saúde 2007).

Embora não seja escopo do estudo, nota-se a tendência deste grupo à exposição aos riscos externos, possivelmente resultando nos eventos. Dentre esses fatores de risco temos o uso de álcool e outras drogas, a violência urbana, imprudência no trânsito e os acidentes de trabalho, além de acidentes. 


\subsection{Condições clínicas}

Clinicamente a maior parte dos pacientes veio ao serviço consciente ou parcialmente consciente $(71,2 \%)$ e com quadro hemodinâmico estável, com pequeno número de pacientes hipotensos $(3,7 \%)$. Isso pode traduzir uma menor gravidade das lesões ou eficiência no serviço de resgate e pronto-atendimento e estabilização pré-hospitalar. Como não há critério de exclusão de resgate, pacientes com sinais vitais, ainda que fracos são prontamente trazidos ao pronto-socorro, assim pacientes de todas os níveis de gravidade são trazidos ao serviço, resultando a hipótese que possivelmente a estabilização pré-hospitalar e o tempo de resgate até o serviço hospitalar são eficientes. Malvestio (2005) mostrou que a reposição volêmica foi o único fator com valor protetor para o risco de óbito em diversas circunstâncias. Isso também favorece a chegada de pacientes mais cooperativos quanto ao exame clínico ou à realização de exames complementares, resultando em benefício aos próprios quanto ao seu diagnóstico e tratamento (Ali et al. 1997). 


\subsection{Tempos}

O fator temporal é fundamental no manejo do trauma e nesse estudo obtiveram-se dados temporais das diversas etapas do atendimento ao politraumatismo no nosso serviço.

O tempo de chegada ao centro hospitalar deu-se em média de 50 minutos, embora a maior parte tenha chegado um pouco antes, em até 45 minutos. Considerando-se uma metrópole como São Paulo, que cronicamente sofre com congestionamentos de trânsito, este tempo é aceitável. Embora tal concatenamento temporal transgrida um pouco o conceito do "Golden Hour" (Cowley 1976), este vem sendo modernamente questionado em relação ao limite real (Bledsoe 2007), estudos demonstram que o conceito de que quanto mais rápido a instauração do tratamento, melhor é o prognóstico do paciente (Tallon 2002). As dúvidas residem no fato de que Cowley não apresentou um trabalho que demonstre realmente um fator temporal específico, apenas o mais rápido possível e que isso pode incluir até os "15 minutos dourados" (Lerner et al. 2001). Em contexto de guerra demonstrou-se aumento de $2 \%$ da taxa de sobrevivência pela redução do tempo médio resgate de 5 horas durante a guerra da Coréia para 1 hora durante a guerra do Vietnã; porém o contexto é outro, além do padrão ser relativo a jovens do sexo masculino e com uma grande quantidade de lesões penetrantes (McNabney 1981), comuns no cenário beligerante, porém menos usual no contexto civil. 
Mesmo após a chegada ao centro hospitalar, a questão temporal é fundamental. Estudo mais recente (Clarke et al. 2002) demonstrou que em pacientes hipotensos e que apresentavam lesões intra-abdominais a probabilidade de óbito aumentava em $1 \%$ a cada 3 minutos no centro de emergência. Assim, mesmo após a admissão do paciente persiste a necessidade do rápido concatenamento dos eventos.

Desta forma, ressalta-se o elevado intervalo médio entre a realização da ultra-sonografia e a tomografia computadorizada, de aproximadamente 150 minutos, embora a moda tenha sido um pouco menor, 120 minutos e até se registrou a realização de exames em até 15 minutos da chegada ao serviço, embora também possa ter demorado além dos limites usuais (420 minutos).

Embora haja uma demora inicial por conta das manobras de reanimação e estabilização do paciente e na necessidade da realização de outras intervenções prioritárias, consumindo-se tempo precioso, tal intervalo elevado entre a realização dos exames também pode ser decorrente da própria da própria dinâmica do serviço. Dentre os fatores de atraso por conta disto temos o elevado número de tomografias solicitadas e realizadas, havendo espera decorrente de fila de exames, a necessidade do preparo oral do paciente para a realização do exame e o tempo de transporte que, embora em curto trajeto, acaba sendo aumentado para pacientes que necessitam de gasoterapia para a remoção. Em alguns pacientes mais 
graves, há otimização na realização do exame, na tentativa de encurtar este tempo, mas esta tem sido mais exceção do que regra.

Assim, o intervalo observado entre os exames realizados foi muito grande no contexto do traumatismo. Não há dados em literatura que estudam especificamente este tempo, permitindo comparação. Tal fato possivelmente ocorre pela diferente dinâmica dos diversos serviços, constituídos pela infra-estrutura dedicada, flexibilidade e pelos protocolos de exames.

No nosso contexto, embora haja uma infra-estrutura mais que adequada, a flexibilidade e os protocolos ainda podem ser otimizados. Para isso devem ser implementados mecanismos de comunicação interna que prontamente identifiquem os pedidos de pacientes traumatizados e priorizeos tanto quanto ao preparo quanto à ordem na fila. Para o preparo, pode se reduzir o tempo de administração do contraste para um tempo de até 10 minutos, pela ingestão de quantidade menor de contraste e o uso de sondas para pacientes desacordados. Como o principal objetivo deste contraste oral é a avaliação de lesões do trato digestivo alto (estômago e arco duodenal) eventualmente para agilizar o processo, poder-se-ia descartar a necessidade do uso do contraste oral (Stuhlfaut et al. 2004), ou utilizando-o apenas na estrita suspeita de lesão duodenal. O tempo de realização da tomografia, não calculado no estudo, varia entre 10 e 20 minutos e depende de uma série de fatores, sendo o posicionamento do paciente no aparelho o principal limitante e em menor grau a necessidade de programação personalizada ao paciente das seqüências de aquisição. Como nosso protocolo inclui uma 
fase excretora a 300 segundos após o início da injeção do contraste (para estudo de possíveis lesões do trato urinário), a espera torna-se necessária, justificando-se o tempo mínimo do estudo, embora esta fase possa eventualmente ser suprimida como rotina e ser utilizada em casos selecionados (Stuhlfaut et al. 2006).

Outro fator que aumenta o tempo do processo é a necessidade de interpretação do exame tomográfico, também não calculado no presente estudo. Os novos equipamentos com tecnologia multidetector são capazes de adquirir imagens com espessura reduzida e que, mantida a extensão do segmento a ser estudado, geram um grande número de imagens, chegando a mais de mil imagens por estudo. A vantagem é notada como melhora da resolução espacial, capaz de distinguir lesões pequenas, pela redução dos erros de interpretação gerados por artefatos de volume parcial e pela possibilidade das reformatações em outros planos além do axial (Wintermark et al. 2002).

Ainda restringindo temporalmente o método é o uso cada vez mais freqüente de estudos de diversos segmentos (p. ex. coluna cervical, tórax, angiotomografias etc.) ou mesmo do corpo inteiro, baseado nesses tomógrafos com tecnologia multidetector (Linsenmaier, Krotz et al. 2002), que demandam tanto tempo de uso do aparelho quanto para interpretação das imagens obtidas. Por último, a necessidade de um examinador experiente é mais um fator que limita a aplicabilidade do método, pois a não concordância entre examinadores experientes e residentes pode chegar a 6,4\%, com cerca de $1,0 \%$ de achados mais relevantes (Carney et al. 2003). 
Para compensar estes contratempos de ordem temporal, temos alguns fatores que resolvem em parte esses problemas, como o uso de estações de trabalho (Kundel et al. 2001), que permitem o estudo consecutivo das imagens, facilitando o processo interpretativo, e o uso de resposta inicial verbal, após uma pesquisa sucinta de lesões nos órgãos-alvo tradicionais e sinais indiretos de lesão como presença de líquido livre, aumento da densidade e borramento dos planos adiposos superficiais e profundos ou fraturas ósseas. Mesmo com estas medidas, ainda é necessário tempo para a resposta final.

Desta forma, embora a capacidade resolutiva da tomografia computadorizada tenha melhorado, o custo deste ganho qualitativo foi o aumento quantitativo no tempo da interpretação das imagens e na documentação do exame.

Desta maneira, no contexto temporal, a ultra-sonografia apresenta uma excelente resolutividade, uma vez que o tempo médio de exame é de apenas 5 minutos e a resposta é imediata, não se necessitando uma etapa intermediária ao diagnóstico como a análise das imagens que ocorre na tomografia computadorizada ou na espera do resultado laboratorial na lavagem peritoneal diagnóstica. Esse tempo observado de 5 minutos foi o documentado e comumente inclui todo o processo, inclusive a revisão do estudo por um operador mais experiente. No entanto, na prática notamos que o tempo para realização do estudo completo por um único observador experiente é bastante inferior ao registrado, de 30 segundos a 3 minutos. 
Assim, este dado pode não corresponder à realidade do exame por ser uma aproximação ou pela necessidade da revisão imediata do estudo por outro examinador.

A variação do tempo também inclui dentre esses fatores a experiência do examinador, aumentando com a menor experiência, que por vezes necessita uma segunda avaliação realizada por um examinador mais experiente para a resolução de dúvidas e o próprio resultado do exame interfere neste fator, pois a detecção de líquido é rápida e resulta imediatamente em exame positivo, enquanto que o exame negativo necessita de um tempo maior para confirmar a ausência de líquido ou lesões intra-abdominais.(Wherrett et al. 1996), como ilustrado pela Figura 5.

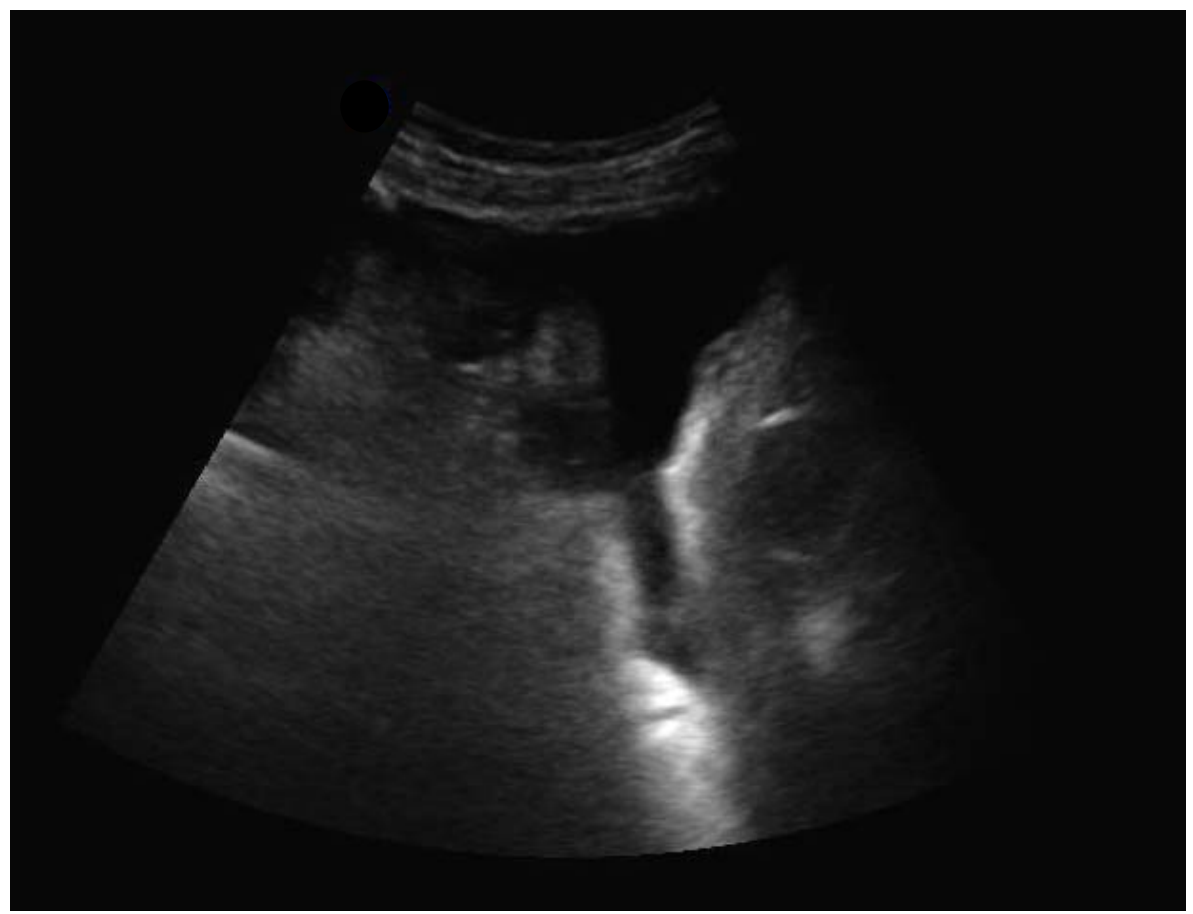

Figura 5 - Exame positivo com grande volume de líquido livre na pelve: a resposta é imediata 


\subsection{Experiência do examinador}

Nem sempre temos à disposição do que seria o examinador mais experiente, por conta da disponibilidade do assistente ou do residente mais graduado, por isso comumente o exame é visto por residentes do $1^{\circ}, 2^{\circ}$ e $3^{\circ}$ ano. Embora essa não seja a situação ideal não houve influência da experiência do examinador em função do número de casos realizados, pois se observou distribuição estatisticamente não-significativa de casos positivos e negativos à ultra-sonografia entre os diversos grupos.

Ao se analisar os falsos positivos, nota-se uma proporção homogênea distribuída entre os residentes (cerca de 10\% a 25\%) e uma proporção maior em relação aos assistentes (40\%). Tal achado pode ser também conseqüência dos casos mais duvidosos serem avaliados por estes. No entanto, ressalva-se que dos 7 casos falso-positivos, embora a tomografia computadorizada não tenha detectado lesão intra-abdominal, o exame foi positivo para a presença de líquido em 5 deles, reduzindo-se a 2 casos em que não havia líquido.

Por outro lado, ao se analisar os falsos negativos, nota-se uma proporção decrescente de acordo com a experiência (9\% no R1, 6\% no R2 e 3\% no R3) que, embora não seja analisável por técnicas estáticas, mostra uma tendência de redução dos casos de acordo com a maior experiência, não sendo observados casos de falso negativo entre os assistentes. 
Assim a experiência do examinador refletiu um baixo número de casos falso negativos e um número relativamente elevado de casos falso positivos. Este fato pode ter um impacto menor, pois implicaria no prosseguimento propedêutico, enquanto que na situação inversa o falso negativo potencialmente não seria mais investigado ou seria investigado tardiamente, com eventual lesão subjacente com retardo no tratamento desta.

A discrepância interobservador no mesmo estudo ultra-sonográfico, embora não especificamente estudada no presente estudo, mostrou-se na prática pequena, fato este sustentado por estudo por Carney (2003) onde o grau de concordância atingiu $99,5 \%$ entre o residente de radiologia e o radiologista assistente.

Desta maneira a necessidade de um examinador mais experiente apresenta pequena vantagem, embora Freza (1999) demonstrou que o desempenho entre técnicos de ultra-sonografia ou radiologistas e cirurgiões seja semelhante. Catan (2003) também notou excelente desempenho da ultra-sonografia de emergência realizada por cirurgiões. Em nosso meio, a ultra-sonografia é praticada apenas por radiologistas sendo a formação específica no próprio pronto-socorro com a realização de diversos casos supervisionados pelos residentes mais graduados ou pelos assistentes.

Com a finalidade de universalização do método, expandindo-se a realização do exame pela equipe médica de atendimento cirúrgico, pode se propor uma formação específica que deveria ultrapassar o requisito mínimo da curva de aprendizado entre 50 e 75 casos supervisionados, além de 
curso teórico com explicações técnicas sobre o método, suas limitações e potenciais armadilhas (Buzzas et al. 1998).

Ainda no contexto da realização do exame existe a possibilidade, para racionalização temporal do método, da realização do exame em ambiente pré-hospitalar que, num estudo (Walcher et al. 2006) demonstrou excelente desempenho com altos valores de sensibilidade, especificidade e acúracia $(93 \%, 99 \%$ e $99 \%)$ maior até que os exames hospitalares, sendo realizado por médicos ou paramédicos emergencistas no local do acidente, sem significativo acréscimo no tempo de resgate e com economia no tempo de diagnóstico. Deste modo, ao chegar no hospital, economiza-se um tempo importante já se respondendo de antemão à questão e dúvidas diagnósticas sobre potenciais lesões intra-abdominais, possibilitando um rápido encaminhamento no seu estadiamento ou tratamento.

\subsection{Ultra-sonografia}

No nosso estudo a ultra-sonografia apresentou desempenho com sensibilidade de 72,7\%, especificidade de 94,6\% e com acurácia de 90,2\% e prevalência de $20,2 \%$, valor preditivo positivo de $77,4 \%$ e o valor preditivo negativo de $93,2 \%$, dentro dos achados da literatura que varia entre $63 \%$ 99\% para sensibilidade e $95-100 \%$ de especificidade (Kimura et al. 1991; Tso et al. 1992; McKenney et al. 1994; Rozycki et al. 1995; Healey et al. 
1996; McKenney et al. 1996; Pearl et al. 1996; McGahan et al. 1997; Thomas et al. 1997; McKenney et al. 1998; Yoshii et al. 1998; Bode et al. 1999; McGahan et al. 1999; Lingawi et al. 2000; Brown et al. 2001; Stengel et al. 2001; Miller et al. 2003; Vassiliadis et al. 2003; Holmes et al. 2004; Shuster, Abu-Laban et al. 2004; Farahmand et al. 2005; Stengel, Bauwens et al. 2005; Lee et al. 2007). A grande variância dos valores de sensibilidade reflete uma grande variedade dos critérios de inclusão de dados e análise. Por exemplo, alguns estudos correlacionam os achados ultra-sonográficos não apenas com outros métodos, mas também com a evolução hospitalar quando outros métodos diagnósticos não foram incluídos inicialmente.

Reavaliando-se os resultados tomográficos, considerando-se como exame positivo aqueles apresentaram líquido livre, observamos que a ultrasonografia apresenta uma sensibilidade de $64,4 \%$, especificidade de $98,3 \%$, acurácia de $88,9 \%$ e prevalência de $27,6 \%$, com valor preditivo positivo de 93,5 \% e valor preditivo negativo de $87,9 \%$.

A piora da sensibilidade ocorre, pois, apesar de se incluir casos em que a tomografia apresentava líquido mas não tinha lesão de víscera parenquimatosa, outros casos negativos à ultra-sonografia evidenciaram líquido à tomografia computadorizada, aumentando o número de falsos negativos, fator este atribuível a erro diagnóstico ultra-sonográfico ou à presença de líquido após a hidratação e demora na realização do exame tomográfico. Por outro lado, a especificidade aumentou ao se reduzir significativamente os falsos positivos. Conseqüentemente temos redução 
discreta da acúracia e melhora do valor preditivo positivo e piora do valor preditivo negativo.

Os dados obtidos evidenciam que a positividade do exame baseia-se praticamente na detecção de líquido livre intra-abdominal, uma vez que este foi o achado mais comum no exame positivo, sendo baixo o número de lesões de víscera parenquimatosa detectados pela ultra-sonografia (apenas 5 casos em 33). A quantidade de líquido caracterizado e a instabilidade do paciente parecem ser fatores que indicam uma maior chance de lesão intraabdominal que requer tratamento (Ma et al. 2001), sendo a presença de líquido isoladamente na pelve um achado mais comum quando não há lesão intra-abdominal, inclusive à tomografia, vagamente reforçado na literatura (Nunes et al. 2001).

O líquido foi encontrado em locais diferentes pelos métodos, sendo mais freqüente à ultra-sonografia no espaço hepatorrenal $(74 \%)$, na pelve $(67 \%)$ e no espaço esplenorrenal $(37 \%)$ e à tomografia computadorizada na pelve $(62 \%)$, espaço hepatorrenal $(51 \%)$ e no espaço esplenorrenal (51\%). A diferença que pode existir em relação ao sítio mais freqüente pode ser resultado do intervalo entre os exames, resultado de um balanço hídrico positivo pela infusão de soro fisiológico e pela própria capacidade de detecção entre os métodos. A infusão de soro é possivelmente o fator gerador desta discrepância, porém só foi anotado a infusão até a ultrasonografia inicial, não se registrando o volume infundido entre os exames.

Rose (2005) avaliou que a presença de líquido no espaço hepatorrenal era um preditor positivo para necessidade de laparotomia 
terapêutica. Dentre nossos casos 20 apresentavam líquido nesse compartimento (todos eles confirmados também pela tomografia) e desses 14 necessitaram cirurgia, confirmando esta tendência.

A quantificação do líquido pode ajudar na tomada de decisão, com o uso de índices de líquido, gerados a partir da soma dos diâmetros anteroposteriores dos bolsões observados à ultra-sonografia, porém tal valor apresenta apenas significado em relação à necessidade de conduta cirúrgica quando o exame for positivo para grandes quantidades de líquido (Huang, Liu et al. 1994; Ma, Kefer et al. 2001; McKenney et al. 2001). Esse achado também foi observado no nosso estudo, onde todos os pacientes com somatória dos bolsões maior que 3,0 cm necessitaram ser submetidos a cirurgia.

A presença isolada de líquido na tomografia computadoriza, um exame mais acurado, sem lesão intra-abdominal permite uma conduta mais conservadora, não necessitando indicação de tratamento cirúrgico imediato em pacientes estáveis (Livingston et al. 2001; Rodriguez et al. 2002), podendo ser observado e até dispensado do setor (Livingston et al. 1998). Tal conduta também é bastante eficaz para crianças, embora este grupo não tenha sido escopo deste trabalho, demonstrado por Somoza (2001) que concluiu que deve ser o tratamento de eleição quando os pacientes estão estáveis. Pode haver discussão sobre esta conduta sob argumento da possibilidade da não-detecção de lesão em vísceras ocas ou hematoma de mesentério pela tomografia computadorizada nestes casos, em que apenas líquido livre é detectado (Yegiyants et al. 2006), retardando o tratamento. Apesar disso, no nosso trabalho nenhum dos pacientes necessitou cirurgia, 
corroborando os achados dos estudos anteriores. Mantida essa ressalva, a pesquisa mais minuciosa de sinais de lesão em vísceras ocas ou hematoma de mesentério deve ser realizada nesses casos.

A limitação da ultra-sonografia na exclusão de lesões de víscera parenquimatosa não permite o uso desse algoritmo, pois a detecção destas lesões foi baixa, em conformidade com a literatura (Poletti et al. 2004), embora estudos mostrem que eles podem ser vistos por observadores experientes com sensibilidade entre $44,4 \%$ e $87,5 \%$ para os diversos órgãos (Sato et al. 2004) e que podem auxiliar o diagnóstico quando não há sinais de hemoperitônio (Brown et al. 2001). Quando encontrados, podem ser sinais sutis de heterogeneidade do órgão (Figura 66) ou alteração do seu contorno (Figura 77).

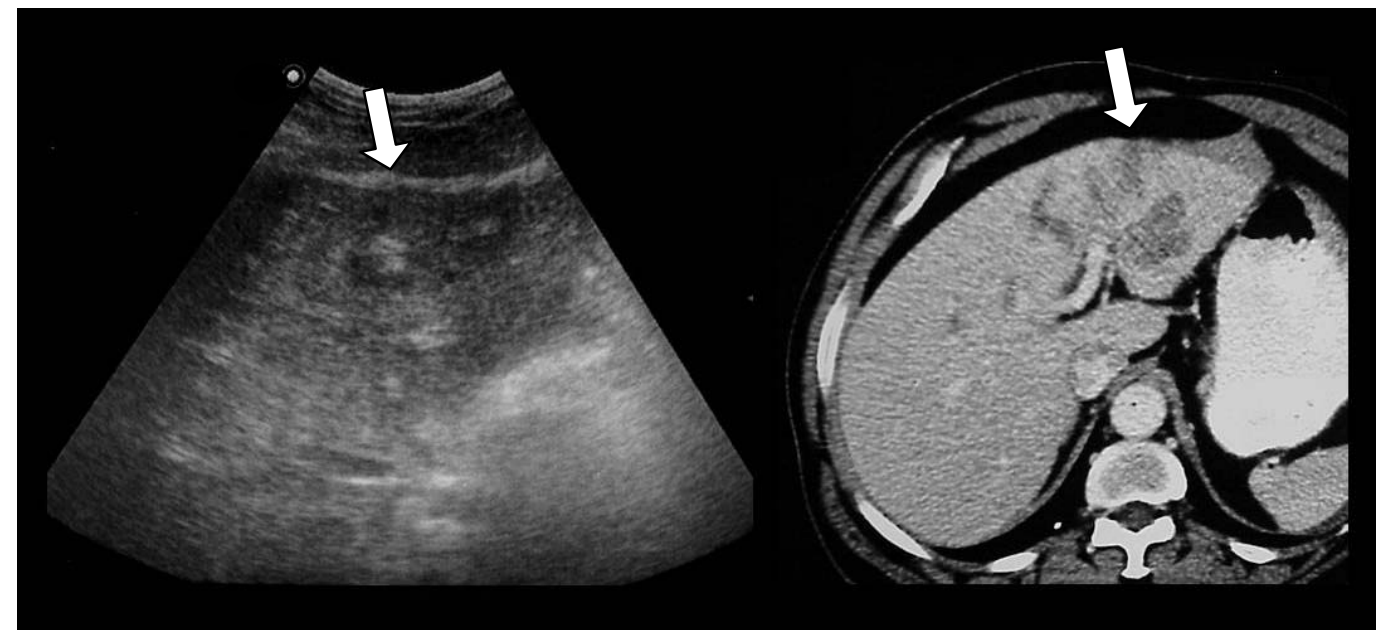

Figura 6 - Lacerações hepáticas superficiais. À US nota-se heterogeneidade da superfície hepática, que à TC evidenciou lacerações mais profundas 


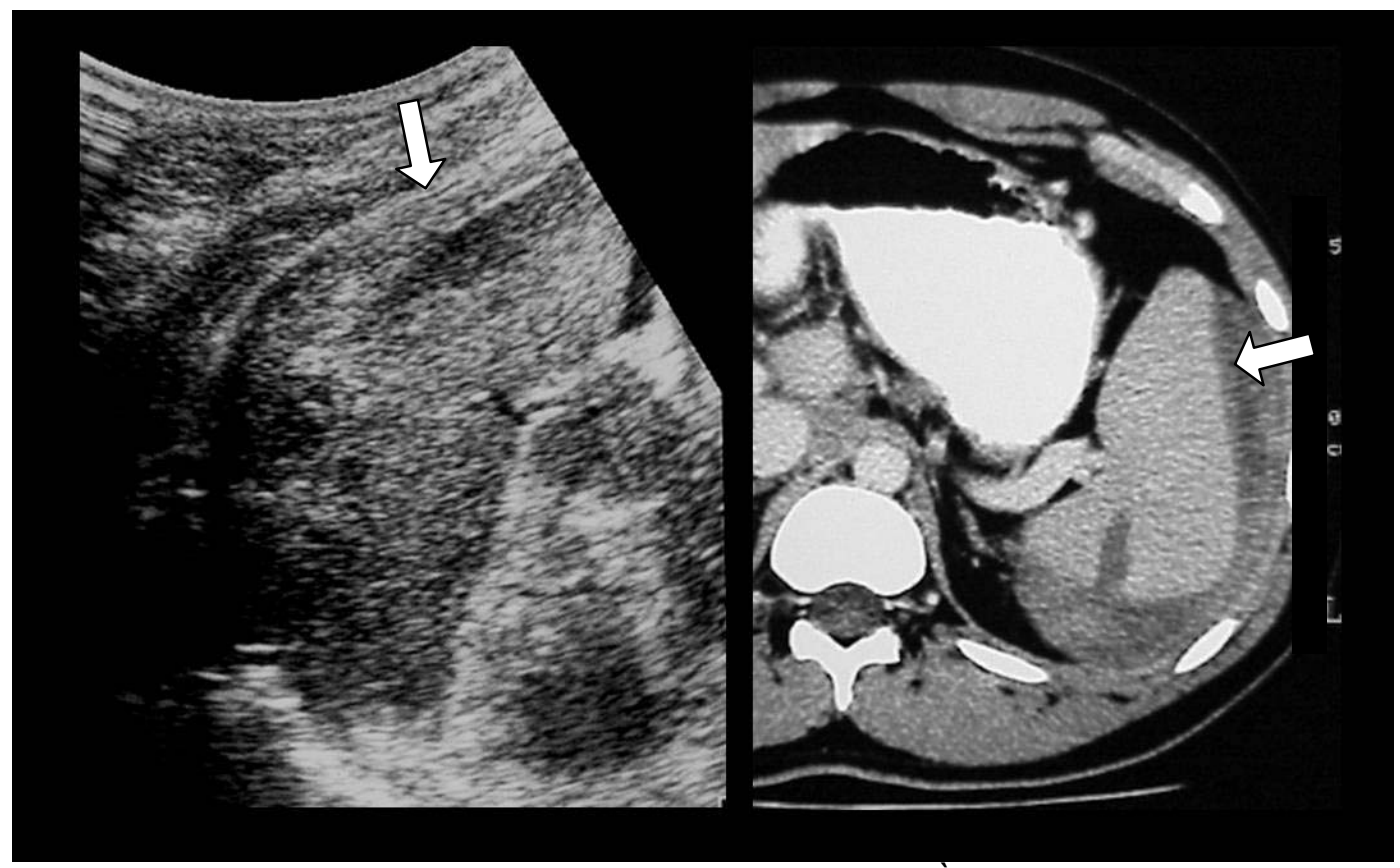

Figura 7 - Laceração esplênica com hematoma subcapsular. À ultra-sonografia nota-se alteração do contorno esplênico com pequena lâmina hipoecogênica junto à capsula esplênica

Sinais indiretos como hematúria também podem ser preditores de lesão do trato urinário, mesmo na ausência de líquido livre (Figura 8), sendo o achado mais valorizável a hematúria macroscópica na inferência de lesões vesicais (Brewer et al. 2007) ou renais (McKenney et al. 1996; Chiu et al. 1997). 


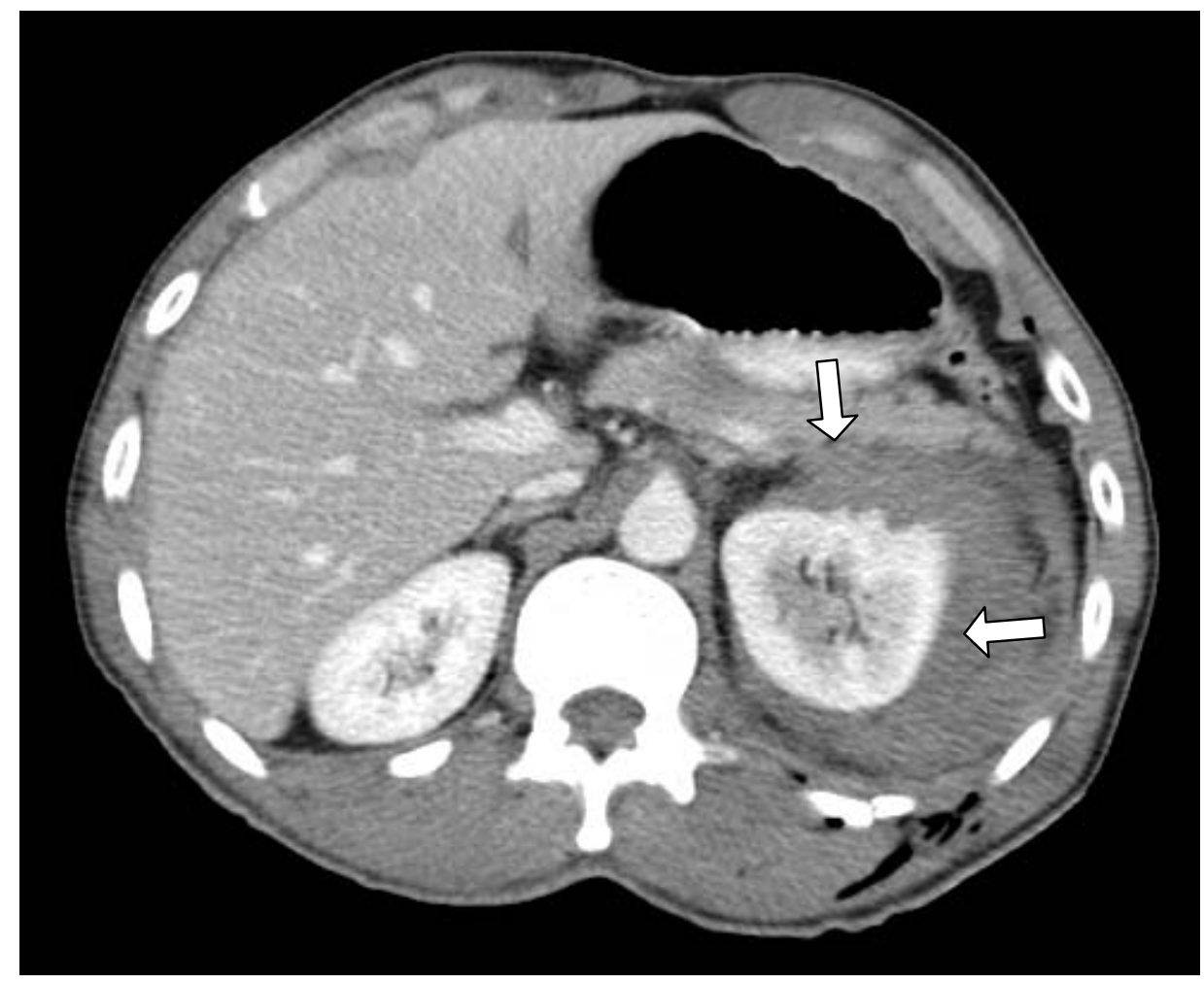

Figura 8 - paciente com US inicial negativo, apresentando hematúria. Suspeita inicial de lesão vesical por fratura de bacia, levando à realização de tomografia computadorizada que demonstrou volumoso hematoma perirrenal

Também é baixa a sensibilidade da ultra-sonografia na detecção de lesões de víscera oca, mesmo com marcas sugestivas como a do "cinto de segurança", relatado pela literatura onde 18 em 23 pacientes com lesão de víscera oca ou hematoma de mesentério apresentaram ultra-sonografia negativa (Stassen et al. 2002). Da mesma maneira, hematomas de mesentério não são achados pela ultra-sonografia no contexto agudo, não sendo observados entre nossos casos, sendo o relato de literatura (Fon et al. 1980) referente a caso tardio e de hematomas volumosos. Na nossa experiência prática, nesses casos por vezes é detectado líquido livre em volume grande e posteriormente a tomografia evidencia a lesão mesentérica ou de víscera oca. 
O desempenho da ultra-sonografia também é afetado quando há fratura de bacia associada com hematomas retroperitoneais, por vezes inacessíveis à ultra-sonografia (Tayal et al. 2006), o que também foi observado em nossa casuística em 4 dos 9 casos falso negativos (Figura 9). Ainda nesse estudo Tayal também observou que a possibilidade do líquido detectado neste contexto possa corresponder a urinoma, fato observado em 7 de 23 casos por ele descritos.

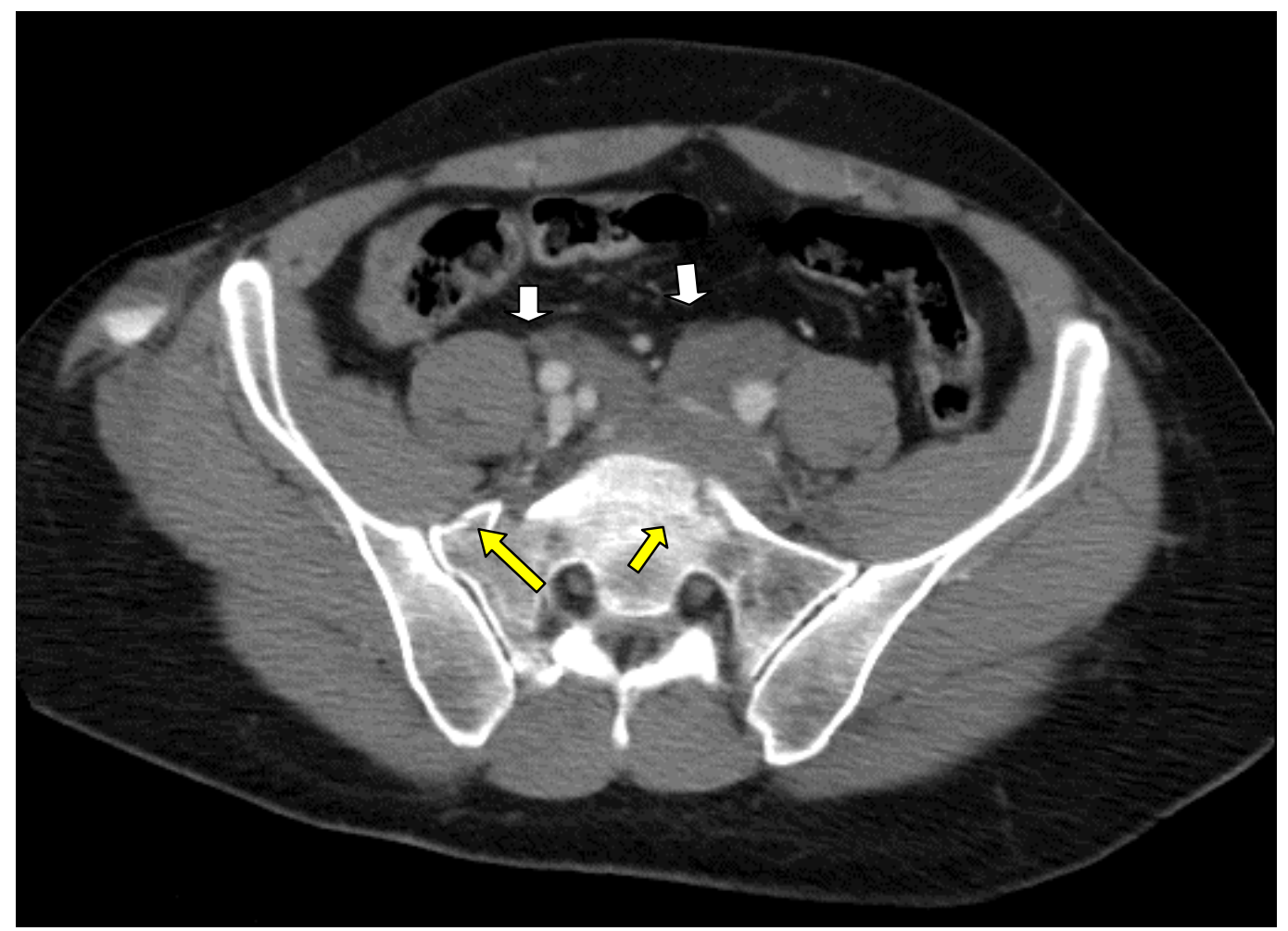

Figura 9 - TC evidenciando hematoma retroperitoneal (setas brancas) secundárias a fratura do sacro (setas amarelas) 
5.6. Outros recursos e manejo de casos

Desta maneira, é conveniente incluir outro método de estudo para prosseguir na avaliação dos exames positivos ou naqueles negativos em que persiste uma suspeita face ao quadro clínico ou exame físico. Dentre as opções, temos a lavagem peritoneal diagnóstica e a tomografia computadorizada.

A lavagem peritoneal diagnóstica neste contexto pode ser redundante mediante à ultra-sonografia positiva, pois a informação necessária pode ser apenas o estadiamento da lesão num paciente estável, porém pode ser útil e complementar se a ultra-sonografia for negativa, houver suspeita clínica persistente e a tomografia computadorizada não for acessível (Baron et al. 1993; Chiquito 1996).

Por sua vez a tomografia vem se estabelecendo como recurso mais efetivo na resolução destes casos, pois define os diferentes graus de lesões, permitindo a decisão clínica adequada (Navarrete-Navarro et al. 1996). Em muitos casos, não é possível excluir lesão intra-abdominal sem o uso da tomografia computadorizada.

Embora este estudo mostre um desempenho satisfatório da ultrasonografia quanto à detecção indireta de lesões através da pesquisa de líquido e ruim na detecção direta de lesões, a evolução dos pacientes mostra um cenário um pouco mais favorável, pois a negatividade da ultra-sonografia mostrou efetivamente menor necessidade de cirurgia e internação, em 
conformidade com recente trabalho (Helling et al. 2007), em proporções próximas às observadas pela tomografia computadorizada. Ressalta-se a presença de uma proporção semelhante entre casos de internação cirúrgica e transferência em função de lesões outras, que resulta igualmente em custo de internação, porém em outro setor.

O melhor desempenho no manejo dos pacientes vítimas de traumatismo sem o uso da tomografia computadorizada é obtido com paciente acordado e consciente, ultra-sonografia negativa, radiografia de tórax normal e exames laboratoriais normais, porém esta combinação é achada em número baixo de pacientes vítimas de politraumatismo (Poletti, Mirvis et al. 2004). Outros estudos, no entanto, indicam que a ultrasonografia consegue racionalizar o uso da tomografia computadorizada (Rose, Levitt et al. 2001; Ollerton et al. 2006), triando os casos com potenciais lesões, permitindo sua priorização.

Um fator que poderia melhorar a capacidade diagnóstica do método seria uma melhor pesquisa e maior atenção às lesões de vísceras parenquimatosas, aumentando a sensibilidade do método e reduzindo o número de falsos negativos (Brown, Casola et al. 2001), embora este processo possa acrescentar um tempo adicional ao processo.

Outras tecnologias podem ser incorporadas ao exame ultrasonográfico tradicional. A principal delas é Doppler, em que é possível realizar o mapeamento vascular. É útil na caracterização de pseudoaneurismas a partir de áreas hipoecogênicas previamente identificadas, porém não acrescenta informações na detecção de líquido livre 
nem sobre lesões de órgãos parenquimatosos (Poletti et al. 2003). Mais recentemente os meios de contraste ultra-sonográficos estão sendo testados no contexto de trauma em modelos animais (Hochmuth et al. 2000; Liu et al. 2002) e em humanos, no contexto agudo (Poletti et al. 2004) ou mesmo tardio (Kalogeropoulou et al. 2006). No primeiro caso a detecção de lesões de órgãos parenquimatosos também não foi satisfatória. A detecção de pseudoaneurismas, no primeiro estudo, e a caracterização de hematoma subcapsular tardio após trauma penetrante no segundo estudo foram as vantagens apontadas. Acrescente-se o fato que há necessidade adicional de aparelho de ultra-sonografia mais sofisticado que o habitual, meio de contraste específico e tempo para a realização do exame.

A presença de lesão intra-abdominal não indica necessariamente tratamento cirúrgico, fato esse observado em um terço dos nossos casos. É preciso um adequado estudo e estadiamento das lesões, na qual a tomografia computadorizada exerce papel fundamental, que permite adequada conduta na indicação cirúrgica. Embora pacientes com instabilidade e hipotensão associados a lesão intra-abdominal formalmente prosseguem com o tratamento cirúrgico, pacientes estáveis podem ser tratados de maneira conservadora (Baron, Scalea et al. 1993) expectante ou com menor invasividade, como tratamento angiográfico, ou aguardar transporte e remoção para centros adequados (Shuster, Abu-Laban et al. 2004).

O grande conflito na conduta mostra-se com os pacientes instáveis cuja ultra-sonografia inicial é negativa, pois não há uma conduta padrão 
definida e deve ser personalizada de acordo com cada paciente. Pode-se optar por repetir a ultra-sonografia, indicar cirurgia ou realizar a tomografia computadorizada, neste último caso avaliando-se cuidadosamente os riscos no transporte do paciente e no tempo total do processo até o seu resultado.

Dessa maneira, a partir dos achados e da prática no nosso centro, é possível utilizar o algoritmo no manejo destes pacientes ilustrado na figura 10, baseado em modelos já consagrados na literatura (Chiquito 1996; McKenney, Martin et al. 1996; Rozycki et al. 1996; McKenney et al. 1997; Nordenholz et al. 1997; Blackbourne et al. 2004).

Assim, após a análise dos nossos dados, consideramos que a ultrasonografia na sala de emergência apresenta um papel importante na avaliação inicial de pacientes vítimas de trauma abdominal fechado. 


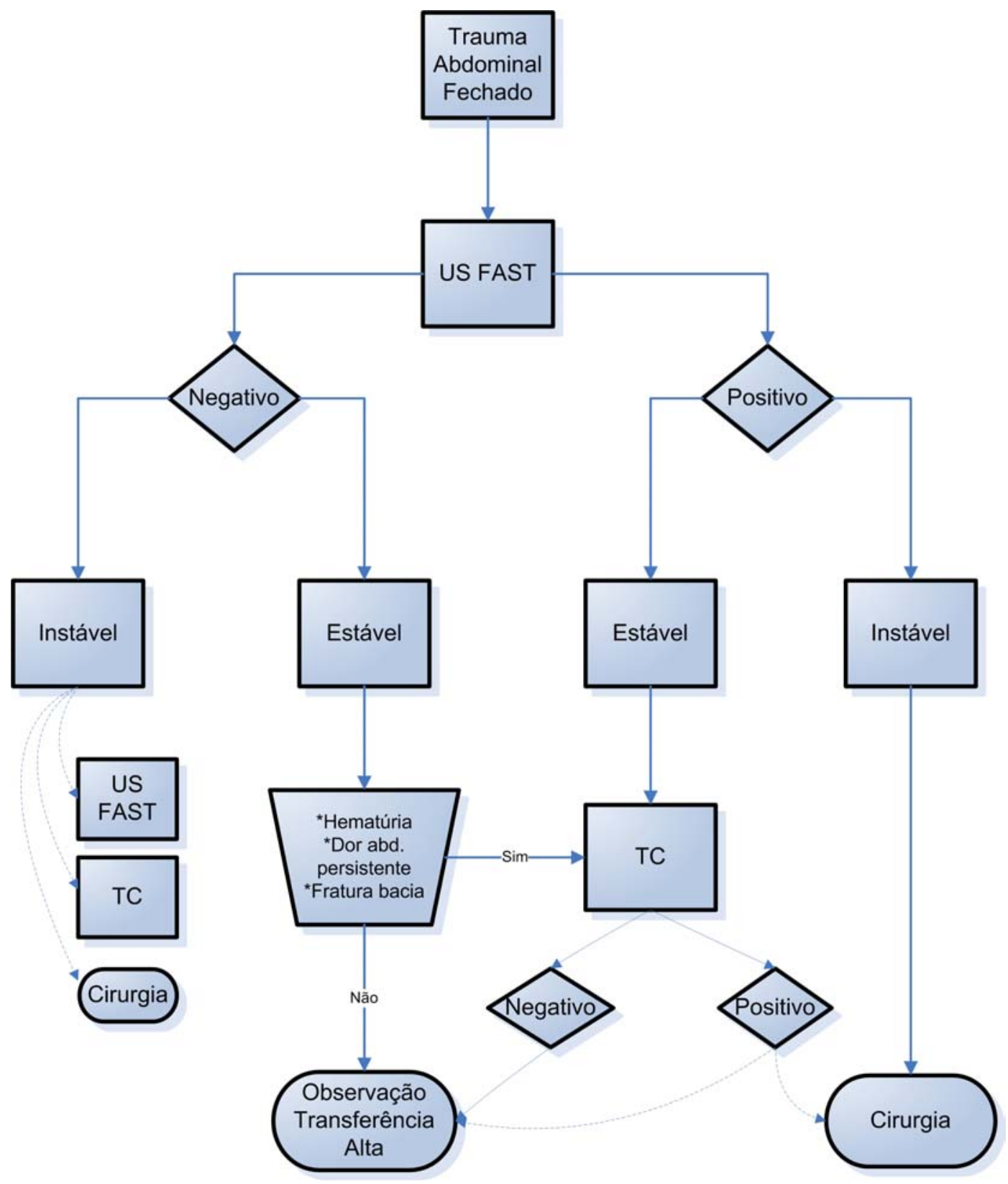

Figura 10 - Algoritmo de avaliação do trauma 
6. CONCLUSÃO 
1. A ultra-sonografia apresentou adequada sensibilidade e boa especificidade na detecção de lesões intra-abdominais, desempenho comparável à da literatura na avaliação inicial do doente vítima de trauma abdominal fechado.

2. A ultra-sonografia apresentou baixa capacidade na detecção direta de lesão de órgãos parenquimatosos.

3. A presença de lesão de intra-abdominal não foi associada a líquido livre intra-peritoneal em cerca de $24,2 \%$ dos casos de acordo com os achados de tomografia computadorizada

4. A ultra-sonografia apresenta capacidade satisfatória na triagem dos pacientes vítimas de trauma abdominal fechado, fornecendo subsídios para avaliação clínica, porém não prescinde dos demais dados para determinar decisões sobre a conduta com o paciente 
Anexos 
ANEXO 1FICHA DE DADOS

Etiqueta PSC ou XCLINIC

PROTOCOLO FAST NO TRAUMA BDOMINAL FECHADO (FAST-TAF)

Dados do trauma

- Auto x auto: $\square$ Motorista $\square$ Passageiro Frente $\square$ Passageiro Traseira

- Auto x moto: $\square$ Auto $\square$ Moto $\square$

- Pedestre x $\square$ Moto $\square$ Auto $\square$ Ônibus/Caminhão

$\square$ Queda metros $\square$ Outro

$\Delta \mathrm{T} \square 15$ minutos $\square 30$ minutos $\square 45$ minutos $\square 60$ minutos

$\mathrm{PA}-\frac{1}{l}{ }_{\mathrm{FC}}^{\mathrm{FC}} \mathrm{G}_{\text {(Sala) }}^{\mathrm{G}}$

Volume infundido até o exame $\mathrm{ml}$ 
FAST - Residente $1^{\circ}$. e $2^{\circ}$. anos Início Término

Derrame pericárdico

$\square$ Não $\square$ $\mathrm{cm}$

Derrame pleural (Axial)

$\square$ Não $\square$ Dir cm $\square$ Esq

Hepatorrenal

$\square 0 \square$ $\mathrm{cm}$

Sem lesão víscera parenquim Duvidosa lesão

Lesão

Esplenorrenal

$\square 0 \square$ $\mathrm{cm}$

Sem lesão víscera parenquim Duvidosa lesão Lesão

Pelve

$\square 0 \square$ $\mathrm{cm}$

Bexiga $\square$ Sondada $\square$ Cheia $\square$ Vazia $\square$ Sem lesão vísceras

$\square$ Duvidosa lesão

$\square$ Lesão

$\square$ Hematoma retroperitoneal

Espessura máxima (AP) $\mathrm{VCl}$ no plano de Corte Tronco Celíaco ou AMS. (imagem no plano axial) $\mathrm{cm}$.
FAST - Residente ou Assistente Início Término

Derrame pericárdico

$\square$ Não $\mathrm{cm}$

Derrame pleural (Axial)

$\square$ Não $\square$ Dir $\mathrm{cm} \square$ Esq

Hepatorrenal

$\square 0 \square \quad \mathrm{cm}$

Sem lesão víscera parenquim

Duvidosa lesão

Lesão

Esplenorrenal

$\square 0 \square$ $\mathrm{cm}$

$\square$ Sem lesão víscera parenquim

Duvidosa lesão

Lesão

Pelve

$\square 0 \square$ $\mathrm{cm}$

Bexiga $\square$ Sondada $\square$ Cheia $\square$ Vazia

$\square$ Sem lesão vísceras

$\square$ Duvidosa lesão

$\square$ Lesão

Hematoma retroperitoneal

Espessura máxima (AP) VCI no plano de Corte Tronco Celíaco ou AMS.

(imagem no plano axial) $\mathrm{cm}$.

R3/R4

Assistente 
TC Abdome - Protocolo trauma

$\Delta$ tempo entre US e TC

Derrame pericárdico

$\square$ Não $\square$ $\mathrm{cm}$

Derrame pleural (Axial) - Maior diâmetro transverso

$\square$ Não $\square$ Dir $\mathrm{cm} \square \mathrm{Esq}$ $\square$ Contusão torácica $\square$ Lesão vascular

$\square$ Fratura costelas $\square$ Direita $\square$ Esquerda Hepatorrenal

$\square 0 \square$ $\mathrm{cm}$

$\square$ Sem lesão víscera parenquimatosa

$\square$ Laceração hepática $\square$ Única $\square$ Múltipla $\mathrm{cm}$ profundidade (a única ou a maior da múltipla) $\square$ Fratura hepática $\square$ Explosão $\square$ Hematoma periepático

$\square$ Lesão renal $\square$ Vascular $\square$ Laceração $\square$ Fratura $\square$ Hematoma perirrenal $\square$ Urinoma

\section{Esplenorrenal}

$\square 0 \square$ $\mathrm{cm}$

$\square$ Sem lesão víscera parenquim

$\square$ Laceração esplênica $\square$ Única $\square$ Múltipla única ou a maior da múltipla) $\square$ Fratura esplênica $\square$ Explosão

$\square$ Hematoma periesplênico

$\square$ Lesão renal $\square$ vascular $\square$ Laceração $\square$ Fratura $\square$ Hematoma perirrenal $\square$ Urinoma

$\square$ Pâncreas

Vísceras ocas $\square$ extravasamento do contraste $\square$ Pneumoperitônio

$\square$ Espessamento parietal $\square$ Hematoma meso

Pelve

$\square 0 \square$ $\mathrm{cm}$

$\square$ Hematoma retroperitoneal

$\square$ Lesão vesical $\square$ Intraperitoneal $\square$ Extraperitoneal

Espessura máxima (AP) VCl no plano de corte Tronco Celíaco ou AMS.

(imagem no plano axial) $\mathrm{cm}$

$\square$ Fratura coluna torácica $\square$ Lesão coluna lombar

$\square$ Fratura bacia $\square$ pube $\square$ ísquio $\square$ ilíaco $\square$ sacro 
Evolução

Cirurgia

\section{$\square$ Sem lesões}

$\square$ Laceração hepática $\square$ Única $\square$ Múltipla $\square$ Fratura hepática $\square$ Explosão

$\square$ Hepatectomia parcial segmento

$\square$ Damage control

$\square$ Lesão vascular $\square$ Rafia $\square$ Ligadura $\square$ Ponte $\square$ Embolização

Lesão renal $\square$ Dir $\square$ Esq $\square$ Laceração $\square$ Fratura

$\square$ Rafia renal $\square$ Nefrectomia parcial $\square$ Nefrectomia total

$\square$ Lesão vascular $\square$ Rafia $\square$ Ligadura $\square$ Ponte $\square$ Embolização

$\square$ Laceração esplênica $\square$ Única $\square$ Fratura esplênica $\square$ Explosão

$\square$ Rafia $\square$ Esplenectomia

Lesão víscera oca $\square$ delgado

$\square$ cólon

$\square$ Rafia $\square$

Ressecção

Lesão meso $\square$ conservador $\square$ retirada de hematoma

Lesão vesical $\square$ intraperitoneal $\square$ extraperitoneal

$\square$ Rafia bexiga $\square$ cistostomia $\square$ sondagem

Hematoma retroperitoneal

Tratamento conservador (controle evolutivo)
Alta ( $\square$ Casa $\square$ Ortopedia)
Internação
$\square$ Infecção $\square$ Tórax $\square$ Abdominal e pélvica
$\square$ Choque 
Referências Bibliográficas 
Alexander RH, Proctor HJ and American College of Surgeons. Committee on Trauma., Eds. 2004. Advanced trauma life support program for physicians : ATLS. Chicago, II, American College of Surgeons.

Ali J, Adam RU, Gana TJ, Bedaysie H and Williams JI. Effect of the prehospital trauma life support program (PHTLS) on prehospital trauma care. J Trauma. 1997;42:786-790.

Ammann AM, Brewer WH, Maull KI and Walsh JW. Traumatic rupture of the diaphragm: real-time sonographic diagnosis. AJR Am J Roentgenol. 1983;140:915-916.

Arrillaga A, Graham R, York JW and Miller RS. Increased efficiency and costeffectiveness in the evaluation of the blunt abdominal trauma patient with the use of ultrasound. Am Surg. 1999;65:31-35.

Asher WM, Parvin S, Virgillo RW and Haber K. Echographic evaluation of splenic injury after blunt trauma. Radiology. 1976;118:411-415.

Baron BJ, Scalea TM, Sclafani SJ, Duncan AO, Trooskin SZ, Shapiro GM, et al. Nonoperative management of blunt abdominal trauma: the role of sequential diagnostic peritoneal lavage, computed tomography, and angiography. Ann Emerg Med. 1993;22:1556-1562.

Birolini D. Como anda a epidemia de trauma. Revista da Associação Médica Brasileira. 2001;47:3.

Blackbourne LH, Soffer D, McKenney M, Amortegui J, Schulman CI, Crookes $B$, et al. Secondary ultrasound examination increases the sensitivity of the FAST exam in blunt trauma. J Trauma. 2004;57:934-938.

Bledsoe BE. Have we set the bar too high? The realities of prehospital care vs. myths of the past. Jems. 2007;32:113-119. 
Bode PJ, Edwards MJ, Kruit MC and van Vugt AB. Sonography in a clinical algorithm for early evaluation of 1671 patients with blunt abdominal trauma. AJR Am J Roentgenol. 1999;172:905-911.

Brewer ME, Wilmoth RJ, Enderson BL and Daley BJ. Prospective comparison of microscopic and gross hematuria as predictors of bladder injury in blunt trauma. Urology. 2007;69:1086-1089.

Brown MA, Casola G, Sirlin CB and Hoyt DB. Importance of evaluating organ parenchyma during screening abdominal ultrasonography after blunt trauma. J Ultrasound Med. 2001;20:577-585.

Brown MA, Casola G, Sirlin CB, Patel NY and Hoyt DB. Blunt abdominal trauma: screening us in 2,693 patients. Radiology. 2001;218:352-358.

Buzzas GR, Kern SJ, Smith RS, Harrison PB, Helmer SD and Reed JA. A comparison of sonographic examinations for trauma performed by surgeons and radiologists. J Trauma. 1998;44:604-608.

Carney E, Kempf J, DeCarvalho V, Yudd A and Nosher J. Preliminary interpretations of after-hours CT and sonography by radiology residents versus final interpretations by body imaging radiologists at a level 1 trauma center. AJR Am J Roentgenol. 2003;181:367-373.

Carvalho AX, Cerqueira DRC, Rodrigues RI and Lobão WJA. Custo das Mortes por Causas Externas no Brasil. Texto para Discussão IPEA 2007. Disponível em http://www.ipea.gov.br/sites/000/2/publicacoes/tds/td_1268.pdf

Catán GF, Constante S W, Castro C J P, Uribe MM, Julio AR, Villao MD et al. Ecografía en trauma, una herramienta útil en manos del cirujano de urgencia. Rev. chil. cir. 2003; 55:461-465,

Chiquito PE. Blunt abdominal injuries. Diagnostic peritoneal lavage, ultrasonography and computed tomography scanning. Injury. 1996;27:117124. 
Chiu WC, Cushing BM, Rodriguez A, Ho SM, Mirvis SE, Shanmuganathan K, et al. Abdominal injuries without hemoperitoneum: a potential limitation of focused abdominal sonography for trauma (FAST). J Trauma. 1997;42:617625.

Clarke JR, Trooskin SZ, Doshi PJ, Greenwald L and Mode CJ. Time to laparotomy for intra-abdominal bleeding from trauma does affect survival for delays up to 90 minutes. J Trauma. 2002;52:420-425.

Cowley RA. The ressucitation and stabilization of major multiple trauma patients in a trauma center environment. Clin Med. 1976;83:16-22.

Cowley RA, Hudson F, Scanlan E, Gill W, Lally RJ, Long W, et al. An economical and proved helicopter program for transporting the emergency critically ill and injured patient in Maryland. J Trauma. 1973;13:1029-1038.

Farahmand N, Sirlin CB, Brown MA, Shragg GP, Fortlage D, Hoyt DB, et al. Hypotensive patients with blunt abdominal trauma: performance of screening US. Radiology. 2005;235:436-443.

Federle MP, Goldberg HI, Kaiser JA, Moss AA, Jeffrey RB, Jr. and Mall JC. Evaluation of abdominal trauma by computed tomography. Radiology. 1981;138:637-644.

Fischer RP, Beverlin BC, Engrav LH, Benjamin Cl and Perry JF, Jr. Diagnostic peritoneal lavage: fourteen years and 2,586 patients later. Am J Surg. 1978;136:701-704.

Fon GT, Hunter TB and Haber K. Utility of ultrasound for diagnosis of mesenteric hematoma. AJR Am J Roentgenol. 1980;134:381-384.

Frezza EE, Ferone T and Martin M. Surgical residents and ultrasound technician accuracy and cost-effectiveness of ultrasound in trauma. Am Surg. 1999;65:289-291. 
Gelfand MJ. Scintigraphy in upper abdominal trauma. Semin Roentgenol. 1984;19:296-307.

Goldstein AS, Sclafani SJ, Kupferstein NH, Bass I, Lewis T, Panetta T, et al. The diagnostic superiority of computerized tomography. J Trauma. 1985;25:938-946.

Hawkins ML, Bailey RL, Jr. and Carraway RP. Is diagnostic peritoneal lavage for blunt trauma obsolete? Am Surg. 1990;56:96-99.

Healey MA, Simons RK, Winchell RJ, Gosink BB, Casola G, Steele JT, et al. A prospective evaluation of abdominal ultrasound in blunt trauma: is it useful? J Trauma. 1996;40:875-885.

Helling TS, Wilson $\mathrm{J}$ and Augustosky $\mathrm{K}$. The utility of focused abdominal ultrasound in blunt abdominal trauma: a reappraisal. Am J Surg. 2007;194:728-733.

Hingson R, McGovern T, Howland J, Heeren T, Winter M and Zakocs R. Reducing alcohol-impaired driving in Massachusetts: the Saving Lives Program. Am J Public Health. 1996;86:791-797.

Hochmuth A, Fleck M, Hauff P, Reinhardt M, Kosmehl H, Hilger I, et al. First experiences in using a new ultrasound mode and ultrasound contrast agent in the diagnosis of blunt renal trauma: a feasibility study in an animal model. Invest Radiol. 2000;35:205-211.

Holm HH and Mortensen T. Ultrasonic scanning in diagnosis of abdominal disease. Acta Chir Scand. 1968;134:333-341.

Holm HH and Northeved A. An ultrasonic scanning apparatus for use in medical diagnosis. Acta Chir Scand. 1968;134:177-181.

Holmes JF, Harris D and Battistella FD. Performance of abdominal ultrasonography in blunt trauma patients with out-of-hospital or emergency department hypotension. Ann Emerg Med. 2004;43:354-361. 
Hoyt DB and Coimbra R 1988. Introduction. Trauma. K Mattox, E Eugene and D Moore. Norwalk, Appleton \& Lange: 420-450.

Huang MS, Liu M, Wu JK, Shih HC, Ko TJ and Lee CH. Ultrasonography for the evaluation of hemoperitoneum during resuscitation: a simple scoring system. J Trauma. 1994;36:173-177.

Kalogeropoulou CP, Ceccotti PC, Leen E and Horgan P. Is contrast enhanced ultrasound an essential tool for liver trauma? J Trauma. 2006;60:233-236.

Kimura A and Otsuka T. Emergency center ultrasonography in the evaluation of hemoperitoneum: a prospective study. J Trauma. 1991;31:20-23.

Kristensen JK, Buemann B and Kuhl E. Ultrasonic scanning in the diagnosis of splenic haematomas. Acta Chir Scand. 1971;137:653-657.

Kundel HL, Polansky M, Dalinka MK, Choplin RH, Gefter WB, Kneelend JB, et al. Reliability of soft-copy versus hard-copy interpretation of emergency department radiographs: a prototype study. AJR Am J Roentgenol. 2001;177:525-528.

Lee BC, Ormsby EL, McGahan JP, Melendres GM and Richards JR. The utility of sonography for the triage of blunt abdominal trauma patients to exploratory laparotomy. AJR Am J Roentgenol. 2007;188:415-421.

Lerner EB and Moscati RM. The golden hour: scientific fact or medical "urban legend"? Acad Emerg Med. 2001;8:758-760.

Lingawi SS and Buckley AR. Focused abdominal US in patients with trauma. Radiology. 2000;217:426-429.

Linsenmaier U, Krotz M, Hauser H, Rock C, Rieger J, Bohndorf K, et al. Whole-body computed tomography in polytrauma: techniques and management. Eur Radiol. 2002;12:1728-1740. 
Liu JB, Merton DA, Goldberg BB, Rawool NM, Shi WT and Forsberg F. Contrast-enhanced two- and three-dimensional sonography for evaluation of intra-abdominal hemorrhage. J Ultrasound Med. 2002;21:161-169.

Liu M, Lee CH and P'Eng F K. Prospective comparison of diagnostic peritoneal lavage, computed tomographic scanning, and ultrasonography for the diagnosis of blunt abdominal trauma. J Trauma. 1993;35:267-270.

Livingston DH, Lavery RF, Passannante MR, Skurnick JH, Baker S, Fabian $\mathrm{TC}$, et al. Free fluid on abdominal computed tomography without solid organ injury after blunt abdominal injury does not mandate celiotomy. Am J Surg. 2001;182:6-9.

Livingston DH, Lavery RF, Passannante MR, Skurnick JH, Fabian TC, Fry DE, et al. Admission or observation is not necessary after a negative abdominal computed tomographic scan in patients with suspected blunt abdominal trauma: results of a prospective, multi-institutional trial. J Trauma. 1998;44:273-280.

Ma OJ, Kefer MP, Stevison KF and Mateer JR. Operative versus nonoperative management of blunt abdominal trauma: Role of ultrasoundmeasured intraperitoneal fluid levels. Am J Emerg Med. 2001;19:284-286.

MacKenzie EJ, Morris JA, Jr., Smith GS and Fahey M. Acute hospital costs of trauma in the United States: implications for regionalized systems of care. J Trauma. 1990;30:1096-1101.

Malvestio MAA. Predeterminantes de sobrevivência em vítimias de acidentes de trânsito submetidas a atendimento pré-hospitalar de suporte avançado à vida [tese]. São Paulo:Escola de Enfermagem, Universidade de São Paulo; 2005

McGahan JP, Richards J and Gillen M. The focused abdominal sonography for trauma scan: pearls and pitfalls. J Ultrasound Med. 2002;21:789-800. 
McGahan JP and Richards JR. Blunt abdominal trauma: the role of emergent sonography and a review of the literature. AJR Am J Roentgenol. 1999;172:897-903.

McGahan JP, Rose J, Coates TL, Wisner DH and Newberry P. Use of ultrasonography in the patient with acute abdominal trauma. $J$ Ultrasound Med. 1997;16:653-663.

McKenney KL, McKenney MG, Cohn SM, Compton R, Nunez DB, Dolich M, et al. Hemoperitoneum score helps determine need for therapeutic laparotomy. J Trauma. 2001;50:650-656.

McKenney KL, McKenney MG, Nuñez DB and Martin L. Cost reduction using ultrasound in blunt abdominal trauma. Emergency Radiology. 1997;4:3-6.

McKenney KL, McKenney MG, Nuñez DB, McDowell L and Martin L. Interpreting the trauma ultrasound: Observations in 62 positive cases. Emergency Radiology. 1996;3:113-117.

McKenney KL, Nunez DB, Jr., McKenney MG, Asher J, Zelnick K and Shipshak $D$. Sonography as the primary screening technique for blunt abdominal trauma: experience with 899 patients. AJR Am J Roentgenol. 1998;170:979-985.

McKenney M, Lentz K, Nunez D, Sosa JL, Sleeman D, Axelrad A, et al. Can ultrasound replace diagnostic peritoneal lavage in the assessment of blunt trauma? J Trauma. 1994;37:439-441.

McKenney MG, Martin L, Lentz K, Lopez C, Sleeman D, Aristide G, et al. 1,000 consecutive ultrasounds for blunt abdominal trauma. J Trauma. 1996;40:607-611.

McNabney WK. Vietnam in context. Ann Emerg Med. 1981;10:659-661.

Miller MT, Pasquale MD, Bromberg WJ, Wasser TE and Cox J. Not so FAST. J Trauma. 2003;54:52-60. 
Mindelzun RE and McCort JJ. Upper abdominal trauma: conventional radiology. Semin Roentgenol. 1984;19:259-268.

Navarrete-Navarro P, Vazquez G, Bosch JM, Fernandez E, Rivera R and Carazo E. Computed tomography vs clinical and multidisciplinary procedures for early evaluation of severe abdomen and chest trauma--a cost analysis approach. Intensive Care Med. 1996;22:208-212.

Nordenholz KE, Rubin MA, Gularte GG and Liang HK. Ultrasound in the evaluation and management of blunt abdominal trauma. Ann Emerg Med. 1997;29:357-366.

Nunes LW, Simmons S, Hallowell MJ, Kinback R, Trooskin S and Kozar R. Diagnostic performance of trauma US in identifying abdominal or pelvic free fluid and serious abdominal or pelvic injury. Acad Radiol. 2001;8:128-136.

Ollerton JE, Sugrue M, Balogh Z, D'Amours SK, Giles A and Wyllie P. Prospective study to evaluate the influence of FAST on trauma patient management. J Trauma. 2006;60:785-791.

Paajanen H, Lahti P and Nordback I. Sensitivity of transabdominal ultrasonography in detection of intraperitoneal fluid in humans. Eur Radiol. 1999;9:1423-1425.

Pearl WS and Todd $\mathrm{KH}$. Ultrasonography for the initial evaluation of blunt abdominal trauma: A review of prospective trials. Ann Emerg Med. 1996;27:353-361.

Perry JF, Jr. A Five-Year Survey of 152 Acute Abdominal Injuries. J Trauma. 1965;147:53-61.

Poletti PA, Kinkel K, Vermeulen B, Irmay F, Unger PF and Terrier F. Blunt abdominal trauma: should US be used to detect both free fluid and organ injuries? Radiology. 2003;227:95-103. 
Poletti PA, Mirvis SE, Shanmuganathan K, Takada T, Killeen KL, Perlmutter $D$, et al. Blunt abdominal trauma patients: can organ injury be excluded without performing computed tomography? J Trauma. 2004;57:1072-1081.

Poletti PA, Platon A, Becker CD, Mentha G, Vermeulen B, Buhler LH, et al. Blunt abdominal trauma: does the use of a second-generation sonographic contrast agent help to detect solid organ injuries? AJR Am J Roentgenol. 2004;183:1293-1301.

Brasil. Ministério da Saúde. Indicadores e Dados Básicos - Brasil - IDB 2006. Brasília: 2006. Disponível em http://tabnet.datasus.gov.br/cgi/idb2006/public.htm

Robertson LS. Reducing death on the road: the effects of minimum safety standards, publicized crash tests, seat belts, and alcohol. Am J Public Health. 1996;86:31-34.

Rodriguez C, Barone JE, Wilbanks TO, Rha CK and Miller K. Isolated free fluid on computed tomographic scan in blunt abdominal trauma: a systematic review of incidence and management. J Trauma. 2002;53:79-85.

Root HD, Hauser CW, McKinley CR, Lafave JW and Mendiola RP, Jr. Diagnostic Peritoneal Lavage. Surgery. 1965;57:633-637.

Rose JS, Levitt MA, Porter J, Hutson A, Greenholtz J, Nobay F, et al. Does the presence of ultrasound really affect computed tomographic scan use? A prospective randomized trial of ultrasound in trauma. J Trauma. 2001;51:545550.

Rose JS, Richards JR, Battistella F, Bair AE, McGahan JP and Kuppermann $\mathrm{N}$. The fast is positive, now what? Derivation of a clinical decision rule to determine the need for therapeutic laparotomy in adults with blunt torso trauma and a positive trauma ultrasound. J Emerg Med. 2005;29:15-21.

Rozycki GS. Abdominal ultrasonography in trauma. Surg Clin North Am. 1995;75:175-191. 
Rozycki GS, Ochsner MG, Schmidt JA, Frankel HL, Davis TP, Wang D, et al. A prospective study of surgeon-performed ultrasound as the primary adjuvant modality for injured patient assessment. J Trauma. 1995;39:492-500.

Rozycki GS and Shackford SR. Ultrasound, what every trauma surgeon should know. J Trauma. 1996;40:1-4.

Sato $\mathrm{M}$ and Yoshii $\mathrm{H}$. Reevaluation of ultrasonography for solid-organ injury in blunt abdominal trauma. J Ultrasound Med. 2004;23:1583-1596.

Schreiber MA, Gentilello LM, Rhee P, Jurkovich GJ and Maier RV. Limiting computed tomography to patients with peritoneal lavage-positive results reduces cost and unnecessary celiotomies in blunt trauma. Arch Surg. 1996;131:954-959.

Schurink GW, Bode PJ, van Luijt PA and van Vugt AB. The value of physical examination in the diagnosis of patients with blunt abdominal trauma: a retrospective study. Injury. 1997;28:261-265.

National Academy of Sciences. 1966. Accidental Death and Disability: The Neglected Disease of Modern Society. Washington, National Academy of Sciences / National Research Council: 38.

Shuster M, Abu-Laban RB, Boyd J, Gauthier C, Mergler S, Shepherd L, et al. Focused abdominal ultrasound for blunt trauma in an emergency department without advanced imaging or on-site surgical capability. Cjem. 2004;6:408415.

Somoza Al. Resultados del manejo conservados de los traumatismos abdominales pedátricos no penetrantes. Rev cir inf. 2001: 11:205-210.

Stassen NA, Lukan JK, Carrillo EH, Spain DA and Richardson JD. Abdominal seat belt marks in the era of focused abdominal sonography for trauma. Arch Surg. 2002;137:718-723. 
Stengel D, Bauwens K, Rademacher G, Mutze S and Ekkernkamp A. Association between compliance with methodological standards of diagnostic research and reported test accuracy: meta-analysis of focused assessment of US for trauma. Radiology. 2005;236:102-111.

Stengel D, Bauwens K, Sehouli J, Porzsolt F, Rademacher G, Mutze S, et al. Systematic review and meta-analysis of emergency ultrasonography for blunt abdominal trauma. Br J Surg. 2001;88:901-912.

Stuhlfaut JW, Lucey BC, Varghese JC and Soto JA. Blunt abdominal trauma: utility of 5-minute delayed CT with a reduced radiation dose. Radiology. 2006;238:473-479.

Stuhlfaut JW, Soto JA, Lucey BC, Ulrich A, Rathlev NK, Burke PA, et al. Blunt abdominal trauma: performance of $\mathrm{CT}$ without oral contrast material. Radiology. 2004;233:689-694.

Tallon JM. The "golden hour" paradigm. Acad Emerg Med. 2002;9:760; author reply 760 .

Tayal VS, Nielsen A, Jones AE, Thomason MH, Kellam J and Norton HJ. Accuracy of trauma ultrasound in major pelvic injury. $J$ Trauma. 2006;61:1453-1457.

Thomas B, Falcone RE, Vasquez D, Santanello S, Townsend M, Hockenberry $\mathrm{S}$, et al. Ultrasound evaluation of blunt abdominal trauma: program implementation, initial experience, and learning curve. J Trauma. 1997;42:384-390.

Trunkey DD. Trauma. Sci Am. 1983;249:28-35.

Tso P, Rodriguez A, Cooper C, Militello P, Mirvis S, Badellino MM, et al. Sonography in blunt abdominal trauma: a preliminary progress report. $J$ Trauma. 1992;33:39-44. 
Vassiliadis J, Edwards R, Larcos G and Hitos K. Focused assessment with sonography for trauma patients by clinicians: Initial experience and results. Emerg Med (Fremantle). 2003;15:42-48.

Walcher F, Weinlich M, Conrad G, Schweigkofler U, Breitkreutz R, Kirschning $\mathrm{T}$, et al. Prehospital ultrasound imaging improves management of abdominal trauma. Br J Surg. 2006;93:238-242.

Wherrett LJ, Boulanger BR, McLellan BA, Brenneman FD, Rizoli SB, Culhane J, et al. Hypotension after blunt abdominal trauma: the role of emergent abdominal sonography in surgical triage. J Trauma. 1996;41:815820.

Wilson CB, Vidrine A, Jr. and Rives JD. Unrecognized Abdominal Trauma in Patients with Head Injuries. Ann Surg. 1965;161:608-613.

Wintermark M, Poletti PA, Becker CD and Schnyder P. Traumatic injuries: organization and ergonomics of imaging in the emergency environment. Eur Radiol. 2002;12:959-968.

Yegiyants S, Abou-Lahoud G and Taylor E. The management of blunt abdominal trauma patients with computed tomography scan findings of free peritoneal fluid and no evidence of solid organ injury. Am Surg. 2006;72:943946.

Yoshii H, Sato M, Yamamoto S, Motegi M, Okusawa S, Kitano M, et al. Usefulness and limitations of ultrasonography in the initial evaluation of blunt abdominal trauma. Journal of Trauma-Injury Infection \& Critical Care. 1998;45:45-51. 